Nueva Revista de Filología Hispánica (NRFH), LXVIII, 2020, núm. 1, 3-46

ISSN 0185-0121; e-ISSN 2448-6558; DOI: 10.24201/nrfh.v68i1.3581

\title{
ESTADOS, TRANSITIVIDAD Y CLÍTICOS
}

\author{
STATES, TRANSITIVITY AND CLITICS
}

\author{
P. Pablo Devís Márquez \\ Universidad de Cádiz \\ pedropablo.devis@uca.es
}

RESUMEN: La existencia en español de construcciones transitivas con predicados estativos y un clítico paradigmático no reflexivo y concordado en número y persona con el sujeto ("El alumno se supo la lección") ocasiona serias dificultades a aquellas propuestas según las cuales un clítico con estas características en construcciones oracionales transitivas o es un operador aspectual que aparece exclusivamente en predicados télicos y durativos, o es un operador aspectual no ligado a la telicidad, o equivale a un marcador que refleja ya sea cierta implicación del sujeto oracional, ya sea una mayor relación entre sujeto y OD. Además de plantear cuáles son esas dificultades, son objetivos de este artículo explicar 1) la compatibilidad de unos predicados estativos transitivos con este clítico frente a la incompatibilidad de otros; 2) la compatibilidad de determinados predicados estativos transitivos con este clítico con algunos OD que son plurales escuetos, y 3) la compatibilidad de determinados predicados estativos transitivos con este clítico con OD que no son plurales escuetos y carecen de determinación explícita.

Palabras clave: predicados estativos; transitividad; clíticos; construcciones pronominales; aspectualidad.

Abstract: The existence in Spanish of transitive constructions with stative predicates and a non-reflexive paradigmatic clitic that agrees with the subject in number and person (El alumno se supo la lección) raises important problems for accounts where this clitic is an aspectual operator that either only occurs with telic and durative predicates or is not related to telicity, or is a marker that conveys some involvement on the part of the sentence subject or a closer relationship between subject and DO. Beside reviewing these problems, the article sets out to explain: 1) the (in)compatibility of some transitive stative predicates with this clitic, 2) the compatibility of certain transitive stative predicates with the clitic when the relevant DOs are bare plurals, and 3) the compatibility of certain transitive stative predicates with the clitic when their DOs are not bare plurals and lack explicit determiners.

Keywords: stative predicates; transitivity; clitics; pronominal constructions; aspectuality.

Recepción: 16 de julio de 2018; aceptación: 18 de diciembre de 2018.

D.R. (C) 2020. Nueva Revista de Filología Hispánica Licencia Creative Commons Attribution-NonCommercial (CC BY-NC) 4.0 International 


\section{INTRODUCGIÓN Y OBJETIVOS}

La existencia de construcciones transitivas con predicados estativos y un clítico paradigmático, no reflexivo y concordado en número y persona con el sujeto, como por ejemplo (1), ocasiona serias dificultades a aquellas propuestas según las cuales un clítico con estas características en estructuras oracionales marcadas por la transitividad o es un operador aspectual que aparece exclusivamente en SV dotados de telicidad y duración, o un operador aspectual no ligado a la telicidad, o equivale a un marcador que refleja ya sea cierta implicación del sujeto oracional, ya sea una mayor relación entre sujeto y $\mathrm{OD}^{1}$ :

\section{(1) El alumno se supo la lección.}

Desde nuestro punto de vista, tales dificultades tienen que ver con una defectuosa caracterización de este clítico, lo que exige la elaboración de una propuesta alternativa capaz de determinar cuál es el valor común que lo identifica en todos estos casos de construcciones transitivas, se trate o no de estados. Dicha propuesta, que supondría, obviamente, el análisis también de estructuras eventivas, sobrepasa las pretensiones de un artículo como éste, centrado exclusivamente en los predicados estativos y, por esta razón, se divulgará en un trabajo actualmente en preparación, cuyo primer borrador se encuentra prácticamente terminado. Lo que sí vamos a tratar en este artículo -de hecho, conforman sus objetivos básicos- son tres cuestiones que restringimos en exclusiva a los estados, que pueden plantearse sin necesidad de resolver con anterioridad el valor real del clítico y requieren explicaciones mucho más breves. En primer lugar, dos cuestiones que, aun habiéndose debatido

1 Sobre la diferencia entre $s e$ paradigmático y se no paradigmático, cf. OTERo 1968 y 2002 y SUÑER 1973. El primero indica tercera persona y alterna con otras formas átonas del pronombre personal correspondientes a personas distintas, como el se reflexivo. No obstante, en tanto que un clítico del tipo de (1) carece de la opción de doblado mediante una forma tónica del pronombre personal introducida por la preposición $a$, el reflexivo sí dispone de esta opción: (i) \{Yo/ Tú/ El alumno/ Nosotros/Vosotros/Ellos\} \{me/ te/ se/ nos/ os/ se\} \{supe/ supiste/ supo/ supimos/ supisteis/ supieron\} la lección ( $\{*$ a mí/*a ti/*a sí/*a nosotros/*a vosotros/*a ellos\}); (ii) $\{\mathrm{Me} / \mathrm{Te} / \mathrm{Se} / \mathrm{Nos} / \mathrm{Os} / \mathrm{Se}\}$ \{peino/ peinas/ peina/ peinamos/ peináis/ peinan\} (\{a mí mismo/ a ti mismo/ a sí mismo/ a nosotros mismos/ a vosotros mismos/ a sí mismos\}). 
en propuestas de otros autores, no parece posible catalogarlas como resueltas: la razón de por qué unos estados pueden aparecer en este tipo de estructuras y otros no, tal y como muestra el contraste entre (1) y (2):

(2) Juan (*se) posee los discos de su padre;

y por qué, cuando se trata de estados que admiten este tipo de construcción, en unos casos el clítico es compatible con OD que son plurales escuetos y en otros no, como evidencia el contraste entre (3) y (4):

(3) *El alumno se supo lecciones.

(4) Los ciudadanos se temen represalias por parte del Gobierno.

En segundo lugar, una tercera cuestión centrada en esclarecer algo que apenas se ha tratado en otras hipótesis: por qué unas veces el clítico es compatible con OD que, sin ser SN escuetos-plurales o no-, carecen de determinación explícita:

(5) (Nos) creemos \{a Juan/ a éste/ a éstos/ eso/ todo\}.

Desarrollaremos estos tres asuntos en "Estados compatibles con el clítico...", si bien, con anterioridad, en "Hipótesis previas y problemas" intentaremos hacer una revisión crítica de propuestas anteriores a la nuestra.

Antes de comenzar, conviene advertir que, en lo que concierne a estas estructuras, vamos a remitirnos exclusivamente a la descripción del estado actual en el que se encuentra, fundamentalmente, la variante peninsular de la lengua española. Las fuentes de datos que se emplean en este artículo proceden de la introspección del propio autor, cuya variante del español es precisamente ésa. Queda la opción, por tanto, de completar este trabajo con otros sobre variantes distintas de la peninsular.

\section{Hipótesis PREVIAS y PROBLEMAS}

Nos centramos en este apartado en los inconvenientes que para propuestas anteriores ha supuesto explicar la compatibilidad de algunos predicados estativos con un clítico no reflexivo 
concordado con el sujeto en construcciones transitivas. En el siguiente subapartado trataremos lo que concierne a lo que denominamos hipótesis aspectual, esto es, aquella que relaciona la presencia del clítico en este tipo de estructuras oracionales con el llamado aspecto léxico. A las dificultades que se desprenden de la propia caracterización del clítico en esta hipótesis puede añadirse una más: el hecho comprobable de que los denominados predicados estativos son un problema en sí mismos desde el momento en que se los presenta como miembros de una misma categoría aspectual, la de los estados. En "Las hipótesis de la implicación del sujeto y de la relación sujeto-OD” proponemos una revisión crítica de otras propuestas ajenas a la aspectual.

\section{Estados, transitividad y clíticos en el ámbito de la hipótesis aspectual}

En lo que respecta a la dificultad que implica la caracterización de los predicados estativos, Cuartero Otal (2007, 2011 y en preparación), Cuartero Otal y Horno Chéliz (2011 y 2012) y Horno Chéliz y Cuartero Otal (2010) señalan como causa el no haberse distinguido entre los estados que corresponden a tipos de Aktionsarten según la información inherente al propio verbo, los que atañen a enunciados construidos con verbos estativos y los que conciernen a enunciados construidos con verbos eventivos reinterpretados. Del mismo modo, reparan en el comportamiento absolutamente dispar que muestran con respecto a las pruebas de identificación que suelen utilizarse para reconocerlos, lo que les lleva a considerar el concepto de estado como concepto fuertemente intuitivo (cf. también Silvagni 2017, pp. 106 ss.). Así, por ejemplo, por una parte, en tanto que hay predicados catalogados como estativos que admiten la prueba de las perífrasis progresivas -positiva sólo, se dice, para los predicados eventivos o no estativos (cf. Vendler 1957, p. 148; y 1967, p. 104)-, otros predicados con la misma catalogación no la admiten. Para comprobarlo, basta acudir al contraste entre (6) y (7):

(6) Últimamente está teniendo mucha fiebre.

(7) *Mis padres están poseyendo dos casas. 
Para Cuartero Otal (2011), en ejemplos del tipo de (6) se produce una reinterpretación de la lectura estativa, que pasa a ser una lectura estativa temporal. Por otra parte, también hay problemas con, por ejemplo, la prueba de la paráfrasis con el verbo ocurrir. Esta prueba debería dar resultados negativos en el caso de los predicados estativos, pues los estados no ocurren, sino que simplemente se dan (cf. De Miguel 1999, pp. 30113012). Sin embargo, de nuevo es posible comprobar cierta disparidad en el comportamiento de este tipo de predicados ${ }^{2}$ :

(8) Ocurre que tiene mucha fiebre.

(9) *Ocurre que mis padres poseen dos casas.

La falta de espacio para profundizar en una discusión teórica acerca del concepto de estado como categoría aspectual nos conmina en este trabajo a aceptar, por ahora, la clasificación de los denominados tipos de predicados que, conforme a la terminología de Vendler (1957 o 1967), se plantea en De Miguel (1999) para la lengua española. Distinguimos en este sentido entre eventos (realizaciones, actividades y logros) y no eventos o estados. Las realizaciones aluden a eventos durativos, dinámicos y télicos:

(10) Mi hermano fumó varios cigarros.

Las actividades se refieren a eventos durativos y dinámicos que carecen de telicidad:

(11) Mi hermano come patatas todos los días.

Los logros coinciden con las realizaciones en que aluden a eventos télicos y dinámicos, pero se diferencian en que muestran un valor puntual y no durativo:

${ }^{2}$ Hechos como éstos exigen dejar de aludir a estas pruebas como un modo de establecer rasgos pertinentes de los estados o dejar de catalogar como estados determinados predicados. Si por clase, en su sentido lógico, se entiende un 'conjunto de individualidades', esto es, de miembros discontinuos que poseen al menos una característica común (cf. FERRATER Mora 1979, pp. 514 ss.), carece de sentido postular la existencia de una clase -la de los estados- en la que algunos de sus miembros no muestran alguna de las características que la definen. 
(12) Este año ya he cruzado la frontera varias veces.

Frente a los eventos, los estados carecen de dinamicidad ${ }^{3}$. A ello añaden que poseen duración y no presentan límites temporales:

(13) El alumno supo la lección.

Entonces, resulta obvio que, si se acepta una clasificación de los tipos de predicados como la anterior, construcciones del tipo de (1) ("El alumno se supo la lección") no podrían catalogarse como unas con lo que algunos han denominado clítico aspectual si, a la vez, se acepta que este clítico exige simultáneamente la telicidad y la duración como características del predicado de la oración en la que se encuentra. Entre quienes así lo hacen destacan autores como Arce Arenales (1989, pp. 297-298), Barra Jover (1996, pp. 125-128), Otero (1999, pp. 1472-1473), De Miguel (1999, pp. 2986 y 2995), Sanz (2000, p. 52), Sánchez López (2002, pp. 109 y 111), Sanz y Laka (2002, p. 310), Kempchinsky (2004, pp. 243-244), Bogard (2006 y 2015), Escobar y Torrens (2007, p. 62), Bosque y Gutiérrez-Rexach (2009, p. 423), RAE (2009, pp. 1707-1708 y 2703), Basilico (2010, p. 275), Campanini y Schäfer (2011), González Vergara (2012, pp. 144 ss.), Camacho Ramírez (2014a, p. 116), Trebisacce (2014, pp. 199-201), etc. ${ }^{4}$ Para ellos, el uso de este clítico, denominado aspectual, sólo es posible en estructuras oracionales que aluden a eventos delimitados (con un principio y un fin), perfectivos ${ }^{5}$, que culminan. En el caso de (10), por ejemplo, el evento se encuentra limitado por dos momentos temporales distintos entre los que se produce una transición

${ }^{3}$ No obstante, sobre una crítica a la falta de dinamicidad como rasgo caracterizador de los estados, cf. CuARTERo Otal 2007, p. 119 y 2011; CuARtero Otal y Horno Chéliz 2011 y 2012, p. 108; Horno Chéliz y Cuartero Otal 2010, p. 83; y Silvagni 2017, pp. 106 ss.

4 En la tradición gramatical hispánica, ya Fernández Ramírez (1986, p. 396) relaciona explícitamente la presencia del clítico con la manera en la que se desarrolla el evento al que alude la estructura oracional completa y dice que con verbos de consumo del tipo de comer y beber, por ejemplo, el clítico exige OD introducidos por un determinante cuyo referente es ingerido completamente por la persona referida por el sujeto.

5 Se emplea el término perfectivo no en el sentido de 'resultado', ni de 'acción completa o puntual', sino en el de 'evento con límites externos' (cf. Comrie 1976, pp. 16 ss.). 
que conduce a un cambio de estado: su inicio, en el que los cigarros todavía no han sido consumidos, y su final, en el que los cigarros han sido consumidos por completo. Por esta razón, piensan, lo siguiente resulta posible ${ }^{6}$.

(14) Mi hermano se fumó varios cigarros.

Cabe entender, por tanto, que este clítico aspectual sólo es factible, según estos autores, en las estructuras transitivas catalogadas como realizaciones, pero no en las actividades, los logros y, sobre todo, los estados. El problema, insistimos, es que (1) -como su versión sin el clítico (cf. 13) - no es una realización. Además, limitar el clítico aspectual en las construcciones transitivas a las realizaciones exige, se dice, que el OD de estas estructuras vaya introducido por un determinante y no pueda tener carácter escueto ${ }^{7}$ :

${ }^{6}$ Algunos autores van más allá y postulan que es el clítico el que dota de telicidad y duración al SV (cf. Gómez López 1993, p. 161; GARRIDo 1996, p. 326; Bogard 2000, p. 50, y 2009, p. 23, n. 45; BENAVIDES 2010, pp. 279-280 e, incluso, SANz 2000, pp. 17, 41, 55 y 64). Idéntico planteamiento es el de Rigau (1994, pp. 35 y 37) para el catalán. Desmiente la idea el contraste entre (10), que igualmente alude a un evento télico y durativo, y (14).

7 Cf. también Laca 1996, p. 246. Masullo (1996, p. 188), en cambio, propone explicar la agramaticalidad del denominado clítico aspectual en construcciones transitivas con OD representados por un SN escueto en términos más sintácticos que semánticos. El hecho de que este clítico equivalga a un núcleo nominal incorporado al verbo -pues representa el argumento externo y absorbe caso-; el de que el SN escueto que funciona como OD necesite incorporarse al verbo para cumplir con la Condición de Visibilidad -un elemento es visible para el marcado temático sólo si se le asigna caso (cf. Chomsky 1986, p. 114) y en ejemplos como éste el caso acusativo estructural que podría ser asignado por el verbo es insuficiente- y el de que los verbos no puedan albergar más de un elemento nominal simultáneamente explican la agramaticalidad de estructuras como (15). El OD de (14), sin embargo, cumple con la Condición de Visibilidad mediante el caso estructural y por eso (14) es gramatical. Bosque (cf. Masullo 1996, p. 187, n. 25) alude a estructuras del tipo prenderse fuego como contraejemplo a la hipótesis de que un verbo no puede albergar más de un elemento nominal a la vez. BosQUE (1996, p. 33) señala que algunas de las restricciones con los SN escuetos pueden tener una base léxica y alude a que verbos existenciales (denotan un suceso en el que surge algo inexistente con anterioridad) son compatibles con $\mathrm{SN}$ escuetos en estructuras inacusativas con clítico, en las que el verbo se vería obligado a albergar dos elementos nominales: (i) "Se produjeron incendios". MAsullo (1996, p. 188, n. 25) arguye que quizás el clítico de (i) no represente el argumento externo y sea distinto del de los verbos llamados 
(15) *Mi hermano se fumó cigarros.

En este mismo sentido, Barra Jover (1996, pp. 125-128) precisa aludiendo al carácter necesariamente contable de estos OD. Sanz y Laka (2002, pp. 324-325) y Bosque y Gutiérrez-Rexach (2009, p. 423) advierten de la necesidad de que estos OD sean complementos de medida o temas incrementales en el sentido de Dowty (1991, § 6) y Tenny (1992 y 1994), esto es, argumentos internos que midan el evento y determinen su final. Pues bien, hay estructuras transitivas estativas con un clítico no reflexivo concordado con el sujeto perfectamente gramaticales cuyo OD es un plural escueto que, obviamente, no puede catalogarse como tema incremental (cf. 4: "Los ciudadanos se temen represalias por parte del Gobierno" ${ }^{8}$. A modo de explicación, Basilico (2010, p. 288) propone que las construcciones

ergativos. Alude en este sentido a la imposibilidad de éstos de aparecer en construcciones resultativas con "estar + participio" ("*[los] incendios están producidos"). Acerca de construcciones como (i), con clítico y verbos existenciales o de efectuación, cf. Devís Márquez 2017. No obstante, sin necesidad de recurrir a ellas, ejemplos del tipo de (ii) representan, pensamos, una dificultad en la hipótesis de que un clítico no reflexivo concordado con el sujeto en construcciones transitivas no es compatible con OD de verbos de consumo, como fumar, que sean SN escuetos: (ii) "Los asistentes al acto se fumaron cigarros de gran calidad".

8 GutiÉRrez Ordóñez (1999, pp. 1910-1911) ofrece ejemplos análogos a (4) aun cuando advierte que el OD de las estructuras con estos clíticos ha de estar determinado y denotar una entidad específica. La opción del clítico, tal como hemos planteado con (ii) de la n. 7, resulta posible igualmente en determinadas estructuras transitivas eventivas cuyo OD es un plural escueto. Así, BARra Jover (1996, p. 126) habla de la posibilidad de OD sin determinante si se añade algún otro elemento que permita la replicabilidad de los nombres contables. Los ejemplos que propone no parecen del todo aceptables: (i) ?? "Se comió \{bocadillos uno detrás de otro/ bocadillos y bocadillos\}”. GARCía Fernández (2011) refiere que, con los verbos que de forma prototípica aceptan el denominado se aspectual, es posible construir ejemplos con plurales sin determinante, pero con complemento nominal: (ii) "Por sus cumpleaños, mis hermanos se comen paellas enormes repletas de marisco". RigAu (1994, p. 33), en cambio, hace referencia a la imposibilidad de OD escuetos en construcciones catalanas análogas: (iii) $a$. "En Pere es llegeix una novella"; $b$. "*En Pere es llegeix novelles". Lo justifica advirtiendo que en estos casos el clítico absorbe el caso partitivo, lo que impide que éste se asigne al OD. No obstante, pensamos, una propuesta como ésta dejaría de explicar ejemplos del tipo: (iv) "En Joan es va menjar entrepans de pernil enormes durant el sopar"; (v) "Els ciutadans es temen represàlies per part del Govern". 
transitivas con este clítico en las que aparecen los denominados predicados estativos son realmente realizaciones en las que el OD ( path complement), mediante el cambio que sufre, permite medir el evento denotado, al que asigna una estructura escalar. Por supuesto, resulta complicado asignar a (4) dicha interpretación, que en la propuesta de Basilico exige que el OD vaya introducido por un determinante.

De todo lo dicho hasta aquí, por consiguiente, puede inferirse que, en tanto que se mantenga la idea de los estados como predicados no eventivos, esto es, como predicados distintos de las realizaciones, los logros y las actividades, la caracterización del llamado clítico aspectual que aparece en las estructuras transitivas como un operador exclusivo de predicados télicos y durativos carece de la posibilidad de explicar la compatibilidad de un clítico no reflexivo concordado con el sujeto con los estados en los que se incluye un OD. No obstante, en el ámbito de la hipótesis aspectual ha habido propuestas que intentan salvar este escollo. La cuestión es que éstas no sólo no alcanzan una solución satisfactoria en este asunto, sino que dejan sin resolver, entre otros, problemas como el de por qué unos estados sí son compatibles con el clítico (cf. 1: "El alumno se supo la lección") y otros no, aun tratándose igualmente de estructuras transitivas (cf. 2, "Juan [*se] posee los discos de su padre", 16 y 17):

(16) Juan (*se) odia las acelgas;

(17) Juan (*se) quiere a Elena;

y el de por qué en unos casos el clítico es compatible con OD que son plurales escuetos (cf. 4) y en otros no (cf. 3: "*El alumno se supo lecciones") ${ }^{9}$.

Es concretamente la dificultad que entrañan los estados si se liga la presencia del clítico de estas construcciones transitivas a la telicidad lo que conduce a Nishida (1994, p. 436) a caracterizar este clítico no como un marcador de telicidad, sino como un marcador de eventos o de estados delimitados cuantitativamente, esto es, de estructuras oracionales en las que hay un homomorfismo entre lo denotado por el OD y el evento o

${ }^{9}$ Los sustantivos contables, obviamente, a no ser que se recategoricen en continuos, no pueden aparecer como singulares escuetos en complementos verbales (cf. BosQUE 1996, pp. 17-18): (i) $a$. "*El alumno se supo lección”; $b$. “*Los ciudadanos se temen represalia por parte del Gobierno”. 
estado al que alude la oración: cada parte de lo denotado por el OD corresponde a una parte del evento o estado y viceversa, de manera que lo denotado por el OD sufre un cambio gradual cuyo final coincide con el del evento o estado. De este modo, en el caso de (14), por ejemplo, el evento termina cuando se consumen por completo los cigarros. Esta propuesta exige que los sintagmas que conforman los OD en este tipo de estructuras sean lo que Krifka (1989 y 1992) denomina sintagmas cuantificados, o delimitados cuantitativamente, y otros, temas incrementales, esto es, sintagmas compuestos por nombres contables y términos de medida (cf. también Verkuyl 1993 y Jackendoff 1996) y no sintagmas con una referencia, que Nishida llama $a c u-$ mulativa, caso, por ejemplo, de aquellos con sustantivos no contables o de aquellos con plurales escuetos (cf. 15) ${ }^{10}$.

Sin embargo, conviene precisar que Nishida identifica esta caracterización con las realizaciones y sólo con algunos estados. Estos últimos, ciertamente, no son télicos, pero en algunos de ellos, señala Nishida (1994, p. 441), existe la misma relación homomórfica entre el complemento verbal y el estado denotado. Así, en un ejemplo como (1) ("El alumno se supo la lección"), habría que entender que la lección queda dividida en una serie de partes diferentes, de las cuales la última coincide con el final del estado al que se alude ${ }^{11}$. La imposibilidad del clítico con otras estructuras oracionales transitivas que denotan estados se justifica, según Nishida, por su calidad de estados no cuantificados, los cuales no pueden dividirse en partes diferentes de manera que se correspondan con las partes en que se divide la referencia del OD (cf. 2, "Juan [*se] posee los discos de su padre", 16 y 17).

${ }^{10}$ Los sustantivos no contables y los contables en los denominados plurales escuetos comparten la propiedad de la referencia acumulativa que Quine (1960, § 19) observó para los no contables. Así, del mismo modo que si algo es, por ejemplo, arena, también lo es cualquiera de sus partes; en el caso de (15), cigarros alude a un tipo de entidades del que cualquiera de sus partes seguiría siendo el mismo tipo de entidades.

11 Esta relación de homomorfía para explicar ejemplos como (1) se encuentra igualmente en BASILICO (2010, p. 288), con la diferencia de que, tal y como ya hemos advertido, este autor caracteriza estas estructuras no como estados, sino como realizaciones. Salvo en esto último, la propuesta de Basilico muestra grandes semejanzas con la de Nishida. Para él, todas las estructuras transitivas con este clítico también presentan una relación homomórfica entre las partes en que se divide el OD (path complement) y aquellas en que lo hace el evento denotado, lo cual permite la medición de éste (cf. BASILICo 2010, p. 282). 
Desde nuestro punto de vista, una valoración global de la propuesta de Nishida exigiría advertir que limitar exclusivamente a las realizaciones y a algunos estados la presencia de un clítico denominado aspectual en las construcciones transitivas suscita ciertos problemas que deberían explicarse. No obstante, por razones que tienen que ver sobre todo con la temática de este artículo, nos centraremos solamente en lo que atañe a los predicados estativos. En este sentido, pensamos, justificar la presencia del clítico en determinados estados por el hecho de que en ellos se establece también una homomorfía entre las partes del estado y las partes en las que se divide lo denotado por el complemento verbal no deja de ser contradictorio si, al mismo tiempo, se acepta que los predicados estativos carecen de límites temporales: ¿cómo hacer coincidir la última parte en que se divide lo denotado por el OD con el final del estado si los estados no culminan? (cf. García Fernández 2011a, p. 187). Además, ¿cómo se explica en la propuesta de Nishida un ejemplo con predicado estativo como (4) ("Los ciudadanos se temen represalias por parte del Gobierno"), en el que la referencia del OD es acumulativa?

Por lo demás, a partir de la propuesta de Pustejovsky (1991) acerca de cómo la estructura interna o subeventiva de los eventos permite establecer sus propiedades aspectuales, lo que implica ciertas modificaciones terminológicas con respecto a la distinción más habitual entre eventos (realizaciones, actividades y logros) y no eventos (estados), De Miguel y Fernández Lagunilla inciden en el cambio de estado como rasgo propio de la fase final de la estructura interna de fases (evento delimitado con duración + estado) del evento completo (cf. Fernández Lagunilla y De Miguel 1999, p. 114, y De Miguel y Fernández Lagunilla 2000, pp. 15 y 28) y no explican el clítico del que se habla en nuestro trabajo como uno télico, delimitador o perfectivo, sino como un operador aspectual que señala que el evento culmina en un punto -su fase final- en que se produce un cambio de estado (cf. también De Miguel y Fernández Lagunilla 2000, p. 29) ${ }^{12}$. Tal estructura eventiva corresponde a lo que estas autoras denominan transición T1, en la que el segundo subevento aparece como lo que ellas llaman "un logro compuesto", pues se trata de eventos delimitados con duración, pero no a lo que

12 Una interpretación sui generis de esta propuesta puede encontrarse en Pérez VázQuez 2002, pp. 201-202. 
llaman "un logro simple", propio este último de los eventos delimitados puntuales (cf. Fernández Lagunilla y De Miguel 1999, p. 114, n. 30, y De Miguel y Fernández Lagunilla 2000, p. 27, n. 17$)^{13}$. La propuesta exige que un determinante introduzca el OD de estas construcciones (cf. Fernández Lagunilla y De Miguel 1999, p. 114, y De Miguel y Fernández Lagunilla 2000, p. 29) y que estas estructuras sean incompatibles con los predicados estativos, ya que éstos aluden a eventos ( sic) simples, con duración y sin fases (cf. Fernández Lagunilla y De Miguel 1999, p. 115, n. 33, y De Miguel y Fernández Lagunilla 2000, pp. 28-29). Ahora bien, en tanto que esto último podría explicar la agramaticalidad de ejemplos del tipo de (2), (16) y (17), carece de utilidad para justificar la gramaticalidad de (1), auspiciada por Fernández Lagunilla y De Miguel 1999, p. 115, n. 33, y en De Miguel y Fernández Lagunilla 2000, p. $28^{14}$.

En primer lugar, la hipótesis de estas autoras parece no tener en cuenta, por ejemplo, la compatibilidad del clítico no reflexivo concordado con el sujeto en estructuras que ni son transiciones $\mathrm{T} 1$ con un logro compuesto, ni expresan estado resultante, ni muestran un determinante en el OD (cf. ii de n. 7: "Los asistentes al acto se fumaron cigarros de gran calidad") o que se caracterizan directamente como lo que ellas denominan transiciones $\mathrm{T} 1$ con un logro simple (cf. 18) ${ }^{15}$ :

${ }^{13}$ En la terminología que emplean Fernández Lagunilla y De Miguel (1999) y De Miguel y Fernández Lagunilla (2000), el concepto de logro compuesto equivale al de realización, esto es, al de "evento delimitado y durativo', en tanto que el de logro simple se identifica con el de logro, es decir, con el de 'evento delimitado no durativo'.

${ }^{14}$ La exigencia de una transición que culmine para que puedan darse estas construcciones supone igualmente un problema para RIGAU (1994, p. 38) a la hora de explicar ejemplos en catalán con predicados estativos del tipo de (i) "Demà en Pere se sabrà la lliçó de memòria".

${ }_{15}$ Azpiazu (2004, p. 18) alude a razones dialectales para explicar ejemplos de transiciones T1 con un logro simple documentadas del tipo de (i) -atribuido a un hablante inmerso en la variante americana del español, Vargas Llosa- que muestran el clítico: (i) "Un ladrón se robó mi computadora". Naturalmente, justificar la presencia del clítico en construcciones como (i) o (18) mediante razones de variación diatópica o geográfica de un mismo sistema lingüístico exigiría, primero, demostrar que es así, lo que supone un estudio comparativo entre todas las variantes diatópicas del español y, segundo, detallar con precisión las zonas en que se produce el fenómeno. A la importancia de la variación estilística y dialectal -CARTAGENA $(1972$, p. 92) ya aludió a la variación diastrática- recurre también MiNGUELL (2012, § 4.3.5.3), incluso cuando se trata de realizaciones del tipo de 
(18) Este año ya me he cruzado la frontera varias veces.

No sería acertado pensar que en la propuesta de estas autoras -como en la de Zagona (1996, pp. 476-477)- el clítico de estos últimos ejemplos carece de valor aspectual y equivale a un mero benefactivo. Son las propias De Miguel y Fernández Lagunilla (2000, p. 23) quienes asignan valor aspectual y no benefactivo al clítico de estructuras como (19a) apoyándose en la compatibilidad de ese clítico con otro de valor benefactivo (cf. 19b); tal como puede observarse, sucede lo mismo con (ii) de n. 7 ("Los asistentes al acto se fumaron cigarros de gran calidad") y con (18) (cf. además 20 y 21):

(19) a. Mi compañero se abrió dos latas en medio segundo.

b. Mi compañero se me abrió dos latas en medio segundo.

(20) Los asistentes al acto se me fumaron cigarros de gran calidad.

(21) Este año ya te me he cruzado la frontera varias veces.

En segundo lugar, para justificar la compatibilidad del clítico en estados del tipo de (1) ("El alumno se supo la lección"), De Miguel y Fernández Lagunilla presuponen en ejemplos como éste la existencia previa de un logro -el de pasar a saber la lección- que desencadena un estado. No obstante, ésta no deja de ser una solución ad hoc en la que el logro previo del que se habla es completamente ajeno al estado al que se alude (cf. Morimoto 2008, p. 593) y que no explica por qué, por ejemplo, en 2 ("Juan [*se] posee los discos de su padre"), 16 ("Juan [*se] odia las acelgas") y 17 (Juan [*se] quiere a Elena), otros estados, no es posible presuponer el logro previo de pasar a poseer los discos de alguien, a odiar las acelgas o a querer a Elena.

García Fernández (2011) propone dejar de llamar aspectuales sólo a aquellos clíticos que aparecen en estructuras transitivas estativas en las que el determinante del sustantivo del OD puede ser elidido sin necesidad de complementación (cf. 22), pero no a aquellos que se encuentran en estructuras transitivas

(14) ("Mi hermano se fumó varios cigarros"). Esta última autora despoja de valor aspectual al clítico de este tipo de construcciones fundamentándose en que también son télicas sin él. 
en las que el determinante del sustantivo del OD exige la complementación para ser elidido (cf. 23a y 23b):

(22) Juan se merecía aplausos y no silbidos.

(23) a. Muchos ciudadanos se creen esos bulos (sobre todo tipo de asuntos).

b. Muchos ciudadanos se creen bulos * (sobre todo tipo de asuntos).

La razón se encuentra, dice, en el hecho de que en las construcciones habitualmente catalogadas como de clítico aspectual el determinante del sustantivo del OD también puede no estar únicamente si dicho sustantivo posee complementación, tal y como sucede en (ii) de n. 7 ("Los asistentes al acto se fumaron cigarros de gran calidad") ${ }^{16}$. Para García Fernández, el clítico de (22) no es aspectual, sino medio o anticausativo ${ }^{17}$. Ello implicaría tener que aceptar en su propuesta que (22) no se forma sobre (24):

(24) Juan merecía aplausos y no silbidos,

sino mediante un cambio diatético que suponga el ascenso del objeto a la posición de sujeto, tal y como sucede, por ejemplo, en el siguiente par con el verbo marear.

(25) a. Juan marea a María.

b. María se marea.

El problema radica, pensamos, en la imposibilidad de encontrar un correlato transitivo para (24) en el que Juan ocupe la posición de objeto. Para García Fernández, todas las construcciones con clítico aspectual -incluidas las estativas que él añade- pueden explicarse mediante las tesis de Nishida (1994), lo que, entre otras muchas cuestiones, supondría volver a encontrar los mismos problemas señalados más arriba a la hora de aplicar la propuesta de la autora japonesa a los predicados estativos con el clítico ${ }^{18}$.

16 Bosque (1996, pp. 80-81) -cf. también SuÑer 1982- apunta cómo los adjetivos y otros complementos restrictivos desempeñan un importante papel en la legitimación de plurales escuetos.

17 Acerca de una reflexión crítica sobre el denominado se medio o anticausativo en español, cf. Devís Márouez 2017.

18 En García Fernández 2015, p. 269, se insiste en calificar el clítico de estas construcciones transitivas como un marcador de telicidad y en ningún 
A diferencia de la propuesta de García Fernández (2011), para Amstrong (2013, pp. 82-84) las estructuras transitivas con un predicado estativo y un clítico no reflexivo concordado con el verbo han de incluirse en el grupo de las que denomina construcciones transitivas de clítico reflexivo -caracterizadas por tener sujetos que no se restringen a los agentes y por tratarse de construcciones que no se restringen a las realizaciones-, frente a las habitualmente consideradas como estructuras con clítico aspectual, que incluye en el ámbito de lo que llama construcciones agentivas de clítico reflexivo, caracterizadas por requerir un sujeto agente, añadir a éste una implicatura convencional (en el sentido de Grice 1975 y Horn 2007) de intencionalidad y ser realizaciones ${ }^{19}$. Ahora bien, no parece aceptable ni que el valor del clítico en lo que Amstrong denomina construcciones agentivas de clítico reflexivo sea el de la confluencia de agentividad, realización e intencionalidad por parte del sujeto, pues esta misma confluencia es factible también en construcciones transitivas en que el clítico reflexivo permite el doblado (cf. 26), ni que en las denominadas transitivas de clítico reflexivo el clítico posea un mero valor negativo -no restricción ni a la agentividad ni a las realizaciones-, ya que, igualmente, ésta es una opción del clítico reflexivo con doblado (cf. 27):

(26) Juan se golpea a sí mismo.

(27) Juan se teme a sí mismo.

A diferencia de Amstrong, MacDonald (2017) cataloga los clíticos en construcciones transitivas con predicados estativos como clíticos aspectuales, aunque no como indicadores de telicidad. Las dos razones fundamentales que ofrece para defender su postura son, primero, que los verbos estativos con los que aparece este clítico son predicados transitivos de otro tipo, esto es, no se trata de lo que Amstrong denomina construcciones agentivas de clítico reflexivo, sino de construcciones transitivas de clítico reflexivo; y segundo, no admiten OD que sean

momento se sugiere la posibilidad de incluir predicados estativos en estas estructuras.

19 Adviértase que nuestra propuesta asigna valor reflexivo exclusivamente a los clíticos con doblado mediante una forma tónica del pronombre personal introducida por la preposición $a$ (cf. n. 1), en tanto que la de Amstrong cataloga como reflexivos clíticos sin la opción de doblado. 
plurales escuetos. No obstante, cabría preguntarse por cuál es ese valor aspectual. Naturalmente, si al tratarse de estados no puede ser el de la telicidad, tampoco podría ser el de la estatividad, pues tales predicados ya son estativos sin la presencia del clítico. Además, en lo que atañe a las razones que ofrece MacDonald, la primera nos retrae a las dificultades de la propuesta de Amstrong para caracterizar las llamadas construcciones transitivas de clítico reflexivo; la segunda quedaría invalidada con ejemplos del tipo de (4) ("Los ciudadanos se temen represalias por parte del Gobierno"). MacDonald (2017) plantea que la supuesta restricción de los OD que son plurales escuetos en las construcciones con el clítico aspectual, desde el momento en que éste también aparece con predicados estativos, no se relaciona directamente con la telicidad, sino con el estatus de sujetos internos de un predicado complejo formado por el verbo y un SP nulo que poseen esos $\mathrm{OD}$. Al igual que los sujetos que son argumentos externos (cf. 28), sugiere MacDonald, los OD en las construcciones con clítico aspectual participan de la restricción del $\mathrm{SN}$ escueto en el que el sustantivo no se encuentra modificado (cf. n. 16), tal y como la reformula Cuervo $(2003 ; 2008$, p. $63 ; 2014$, p. 54 y 2015 , p. 410$)$ a partir de la propuesta inicial de Suñer (1982, p. 209):

(28) *Científicos estudian el asunto ${ }^{20}$.

Ejemplos como (4), pensamos, no podrían explicarse mediante esta tesis ${ }^{21}$.

Por último, ni siquiera sería posible aceptar una razón menor que MacDonald (2017) ofrece para catalogar como aspectual el clítico de los predicados estativos transitivos: la imposibilidad

${ }^{20}$ Acerca de la influencia que factores como el de la presencia de modificadores adverbiales, el establecimiento de relaciones de coordinación entre los argumentos, la complementación del sustantivo, etc., tienen en la posibilidad de sujetos con SN escuetos, cf. TorRego 1989; BosQue 1996, pp. 80-86; Fernández Soriano 1999; Rigau 1999, pp. 326-327; LaCa 1999, pp. 907 ss.; y BosQue y GutiérRez-REXach 2009, pp. 398-400. Contrástese, en este sentido, (28) con, por ejemplo, (i) "Científicos \{así/ como ésos\} estudian el asunto".

${ }^{21}$ Curiosamente, a pesar de que este autor insiste en que el clítico aspectual, frente al clítico reflexivo con doblado, que sí lo es (cf. i), no es compatible con OD escuetos ni puede ser doblado (cf. Huidobro y MacDonald 2007), concluye que ha de ser caracterizado como un OI reflexivo: (i) "Juan se escribió cartas a sí mismo". 
de ser doblados. Si ello se debe a que esto lo acerca al clítico de lo que Amstrong denomina construcciones agentivas con clítico reflexivo, que, igualmente, carece de doblado, cabría entonces plantearse ya no solamente las dudas que en realidad suscita hablar de clítico aspectual en estas estructuras en la propia hipótesis de Amstrong ${ }^{22}$, sino también que la misma característica lo relaciona con clíticos ajenos a estas construcciones, caso de aquellos presentes en estructuras que no son realizaciones, sino actividades (cf. ii de n. 7: "Los asistentes al acto se fumaron cigarros de gran calidad") o logros (cf. 18: "Este año ya me he cruzado la frontera varias veces").

A modo de conclusión de este subapartado, resulta posible inferir que ninguno de los análisis reseñados en el ámbito de la hipótesis aspectual permite explicar convenientemente que algunos predicados estativos coincidan con realizaciones, actividades y logros en su capacitación para ser compatibles con un clítico no reflexivo concordado con el sujeto en construcciones transitivas. Y esto, liguen o no el clítico a la telicidad. Por consiguiente, estos análisis tampoco parecen útiles para resolver alguna de las cuestiones fundamentales que tratamos en este trabajo: establecer criterios que sirvan para dilucidar qué predicados estativos pueden aparecer en este tipo de estructuras transitivas y cuáles no, la compatibilidad del clítico con OD que son plurales escuetos y su compatibilidad con OD que no son plurales escuetos y carecen de determinación explícita.

\section{Las hipótesis de la implicación del sujeto y de la relación sujeto-OD}

Por lo demás, la gramaticalidad de estructuras como (1) ("El alumno se supo la lección") tampoco deja de crear problemas en la propuesta que asigna a estos clíticos no reflexivos concordados con el sujeto en las construcciones transitivas el valor de expresar cierta implicación del sujeto en ellas. Para la inmensa

${ }^{22}$ En tanto que en Amstrong 2013, pp. 91-92, parece aceptarse que sólo el clítico de las denominadas construcciones agentivas de clítico reflexivo es un marcador aspectual de las realizaciones y, por tanto, de telicidad y duración -lo que deja sin explicar la existencia de realizaciones también en el ámbito de las que llama construcciones transitivas de clítico reflexivo-, en Amstrong 2013, p. 124, se concluye que no hay clítico aspectual y que la telicidad en algunas de estas construcciones es sólo uno de los múltiples efectos que produce la incorporación del clítico. 
mayoría de autores que señalan esta implicación, ésta tiene que ver con cierta intencionalidad del referente designado por el sujeto. Es lo que sucede, por ejemplo, en Bello (y Cuervo) (1964 [1860], p. 258), Alonso Cortés (1939, pp. 16-17), Bull (1952, p. 383), Lázaro Carreter (1964, pp. 389-390), Contreras (1966, p. 97), Schroten (1972, p. 90), Alarcos Llorach (1980, p. 218), De Molina Redondo (1974, pp. 61 ss.), Alcina Franch y Blecua (1975, pp. 911 ss.), Gutiérrez Ordóñez (19771978, p. 450 y 1999, pp. 1909-1917), Martín Zorraquino (1979, pp. 107-108, 321 y 336), Cano Aguilar (1981, p. 276), Gooch (1982), Narbona (1984, pp. 180 y 184), Hernández Alonso (1984, pp. 166-167 y 1995, p. 89), García Miguel (1985, p. 341), Arce Arenales (1989, p. 297 y 1994, p. 203), Delbecque y Lamiroy (1996, p. 25), Maldonado (1997, p. 179), Sánchez López (2002, p. 114), Montes Giraldo (2003), D'Introno et al. (2007, pp. 8-10), Bogard (2006, pp. 772-773 y 2015, pp. 36-37) ${ }^{23}$, RAE (2009, p. 2703), Amstrong (2013, pp. 82-84, 89 y 101) ${ }^{24}$, García Fernández (2015, p. 285), etcétera.

Ahora bien, justificar la implicación del sujeto en este tipo de estructuras transitivas con clítico por el hecho de que éste implica la intencionalidad del sujeto exige cierto carácter agen-

${ }^{23}$ Bogard se centra en este caso únicamente en lo que denomina construcciones en las que el clítico es marcador de afectación del sujeto, no en las que alude a un clítico marcador aspectual perfectivo. El clítico que es marcador aspectual perfectivo aparece, según BoGARD (2006, p. 770 y 2015, pp. 2 y 35), solamente en las realizaciones del tipo de (14) ("Mi hermano se fumó varios cigarros"), en las que el OD está semánticamente cuantificado e introducido por un determinante. Cuando este clítico se elide, las oraciones dejan de ser realizaciones y se convierten en actividades (cf. BogARD 2015, p. 35), algo que podría negar un ejemplo como (10) ("Mi hermano fumó varios cigarros"), que no deja de ser una realización. Bogard señala como características pertinentes del clítico marcador de afectación del sujeto el hecho de que la naturaleza aspectual de la construcción -que en ningún momento se explicita, aunque todos los ejemplos presentados sean estativos- no varía si se elide, y el de que, aparezca o no el clítico, el OD no exige determinante: (i) "Mario (se) cree (las) historias que le cuentan". Ahora bien, pensamos, no resulta factible caracterizar el clítico de afectación frente al clítico aspectual por el hecho de que, si se elide, no varía la naturaleza aspectual de la estructura cuando lo mismo sucede en ejemplos con el denominado clítico aspectual, tal y como hemos advertido con el contraste entre (14) y (10).

24 Amstrong se refiere exclusivamente a lo que denomina construcciones agentivas de clítico reflexivo, no a las estructuras que llama construcciones transitivas de clítico reflexivo (cf. supra "Estados, transitividad y clíticos en el ámbito de la hipótesis aspectual”). 
tivo en el argumento externo que no siempre se encuentra presente, tal y como sucede en las construcciones estativas, a las que tampoco parece posible extrapolar en todos los casos el concepto de control de Morimoto (2008) para explicar su compatibilidad en determinados casos con el clítico ${ }^{25}$. Así, en tanto que en (1) podría llegar a pensarse en cierto control por parte del referente del sujeto, resulta complicado plantear que el referente del sujeto en (29) controla el hecho de creerse las historias que le cuentan ${ }^{26}$ :

(29) Mario se cree las historias que le cuentan.

La existencia en español de estructuras del tipo de (1) resulta igualmente problemática para quienes postulan que la presencia de un clítico no reflexivo concordado con el sujeto en construcciones transitivas implica una relación más estrecha entre sujeto y OD que lleva a presentar el primero también como un objeto afectado (cf., entre otros, De Molina Redondo 1974, p. 62; Babcock 1970, pp. 65-66; Strozer 1976; Fernández Ramírez 1986, pp. 395-396; Arce Arenales 1989, p. 297; Zagona 1996, p. 477; Maldonado 2006, p. 214; Bogard 2006 y 2015; Pérez Vázquez 2007; Campanini y Schäfer 2011; Romero Pascual y Teomiro García 2012, p. 241; Teomiro García y Romero Pascual 2012; Camacho Ramírez 2014, pp. 83 ss.). No obstante, en lo que se refiere a los estados, convendría no generalizar y hacer algunas precisiones. Así, Babcock (1970) establece una identidad entre sujeto y OD sólo cuando se trata de construccio-

${ }^{25} \mathrm{El}$ análisis de conceptos como involucramiento e intencionalidad, que pueden llegar a implicar cierta actividad por parte del sujeto, condujo a Morimoto (2008, p. 596) a sustituirlos por el de control para explicar la presencia del clítico con determinados predicados estativos en español, caso de estar. En este sentido, dice, el clítico puede aparecer con los estados cuando se trata de uno que el sujeto puede controlar: (i) "El niño se estuvo \{callado/ *enfermo\}".

${ }^{26}$ En el caso de las construcciones con sujeto agente cuyo referente está dotado de intencionalidad, como (14) ("Mi hermano se fumó varios cigarros"), una hipótesis centrada en la intencionalidad del sujeto debería aclarar la diferencia entre la presencia y la ausencia del clítico. Plantear que la presencia implica cierto énfasis en la intencionalidad sería difícil de aceptar, pues no es la diferencia que mostraría, por ejemplo, el contraste entre (14) y su versión sin el clítico (cf. 10: "Mi hermano fumó varios cigarros"). Tanto es así que ambos serían compatibles con adjuntos que inciden en la intencionalidad o que la niegan: (i) "Mi hermano (se) fumó varios cigarros \{con ahínco/ sin ninguna gana/ por obligación\}". 
nes activas, pero no cuando los verbos son estativos, en los que el clítico, dice, identifica el sujeto con el origen del estado. En el caso de temer, por ejemplo, con la persona de la que procede el temor, algo que no parece aceptable si contrastamos (4) ("Los ciudadanos se temen represalias por parte del Gobierno") con su versión sin el clítico. También en esta última versión, pensamos, cabría identificar el sujeto con la persona en la que se origina el temor. Frente a esto, Bogard (2006 y 2015) restringe la idea del clítico como marcador de sujeto afectado a predicados estativos; Zagona (1996), Campanini y Schäfer (2011), Romero Pascual y Teomiro García (2012) y Camacho Ramírez (2014 y $2014 a$ ), en cambio, sitúan la restricción en las realizaciones ${ }^{27}$.

27 Camacho Ramírez (2014, pp. 83-86 y 2014a), para sostener su hipótesis, parte de la propuesta de que en estas estructuras hay un nudo Causa -justificado sintácticamente a la manera de PyLkKÄNEN (2002 y 2008)-que convierte el sujeto en Causador (Causer), en tanto que el clítico se encarga de convertirlo también en Causado (Causee), como el OD. Intenta demostrar que el sujeto en estas estructuras es un Causado advirtiendo que en ellas no son admisibles adjuntos que contradigan la idea de que el referente del sujeto experimenta un cambio de estado, lo que le lleva a catalogar como inaceptables oraciones completamente gramaticales del tipo de: (i) "Juan se leyó el libro, pero no entendió nada"; (ii) "María se vio Titanic sin llorar". Pruebas análogas presentan Romero Pascual y Teomiro García (2012, p. 241), para quienes el clítico en construcciones transitivas con verbos de consumo no supone telicidad -(i) seguiría mostrando un predicado télico sin $s e-$, sino que se trata de un pronombre marcado con caso Dativo y con un papel temático de experimentante que satura un argumento (un operador lambda $[\lambda]$ en el nivel semántico) introducido mediante una operación léxica de causativización, tal y como la plantea Teomiro García (2010, pp. 242-245; cf. también Teomiro García y Romero Pascual 2012). La relación de anáfora ligada entre sujeto y clítico permite caracterizar el primero como afectado por un cambio de estado. Por lo demás, la demostración de que el sujeto es también un Causador, papel al que vincula el rasgo Control, la hace CAmacho Ramírez aludiendo a la imposibilidad de que estas construcciones admitan adjuntos que anulen ese rasgo. Esto le conduce de nuevo a catalogar como incorrectas estructuras gramaticales: (iii) "Juan se bebió el vino \{accidentalmente/ por obligación\}". Del hecho de considerar afectado el sujeto de estas construcciones se deriva en la propuesta de CAMACHO RAMírez (2014, p. 98) que el clítico se tenga por anáfora, pues a través de él el sujeto termina siendo afectado. En ello coinciden CAMPANINI y SCHÄFER (2011), si bien para éstos el clítico no se relaciona con un nudo causativo, como sí se hace en la hipótesis de Camacho Ramírez, sino que se introduce como especificador de un nudo aplicativo cuya función es expresar una relación de posesión entre el sujeto y el OD. Para CAMPAnini y SchäFer, de lo que se trata en oraciones con verbos de consumo como (14) es de lo que denominan "consumo experiencial" (experiential consumption), que permite 
Ahora bien, se trate o no de estados, justificar una más estrecha relación entre sujeto y OD argumentando que el sujeto es también, como el OD, un afectado en estas construcciones supone pensar que esto es así por el hecho de que la identidad referencial y la concordancia en número y persona que hay entre clítico y sujeto permite establecer esa relación y asignar a este último, además del suyo propio, el mismo papel temático que se asigna al primero: el de afectado $^{28}$, caso análogo al de las construcciones reflexivas, en las que el clítico igualmente es paradigmático, presenta la misma referencia que el sujeto y concuerda en número y persona con éste, con el que mantiene una relación anafórica ligada (correferencialidad y mando-c). Sin embargo, para que esto fuera así, pensamos, habría que aceptar que el clítico no reflexivo concordado con el sujeto en las estructuras transitivas es, como el reflexivo, un complemento verbal al que puede asignársele papel temático; pero he aquí el problema: no lo es. Prueba del carácter de complemento verbal del clítico reflexivo es que admite el doblado mediante una forma tónica del pronombre personal introducida por preposición (cf. 26: "Juan se golpea a sí mismo" y 27: "Juan se teme a sí mismo"). Lo anterior resulta imposible con el clítico no reflexivo al que nos referimos, se trate o no de un estado:

(30) *El alumno se supo la lección a sí.

(31) Mi hermano se fumó varios cigarros a sí.

Además, catalogar los sujetos de las construcciones con estos clíticos como afectados en los que se produce un cambio de estado implicaría aceptar que en ellas tales sujetos podrían serlo, al

que el sujeto posea el OD. Tanto es así que le asignarían un significado del tipo: (iv) "Mi hermano ${ }_{\mathrm{i}}$ causó, fumando, que é $\mathrm{l}_{\mathrm{i}}$ poseyera (de manera inalienable) varios cigarros". La cuestión residiría en cómo justificar entonces la presencia de este clítico en construcciones transitivas con verbos que no son de consumo -los resultados obtenidos por PAZ LOURENÇONI y LeITÃo Martins (2017) en una prueba aplicada a hablantes de español en Chile rebaten la hipótesis que liga este clítico exclusivamente a este tipo de verbosy, tal como plantea Camacho Ramírez, en explicar por qué sería posible establecer la misma relación de posesión entre sujeto y OD cuando el clítico no se encuentra presente.

28 Postura distinta defienden Sanz y LaKa (2002, pp. 322-324), para quienes en este tipo de construcciones no hay relación semántica alguna entre sujeto y clítico. 
mismo tiempo, de construcciones resultativas con "estar + participio". Obviamente, ni de (1) ("El alumno se supo la lección") puede inferirse que "*el alumno está sabido", ni de (14) ("Mi hermano se fumó varios cigarros") que "\#mi hermano está fumado".

Podemos concluir, pues, que, del mismo modo como sucede con la hipótesis aspectual, ni la hipótesis de la implicación del sujeto ligada a la intencionalidad ni la de una mayor relación entre sujeto y OD permiten explicar la compatibilidad de los predicados estativos -tampoco la de los eventivos- con un clítico no reflexivo concordado con el sujeto en construcciones transitivas. Frente a la aspectual, que sí lo hace en parte, las dos hipótesis analizadas en este apartado ni siquiera se plantean el establecimiento de criterios que deslinden los predicados estativos compatibles con este tipo de estructuras transitivas de los que no lo son y que aborden la compatibilidad del clítico con OD que son plurales escuetos y con OD que no son plurales escuetos y carecen de determinación explícita.

ESTADOS COMPATIBLES CON EL CLÍTICO, OD QUE SON PLURALES ESCUETOS Y OD NO ESCUETOS SIN DETERMINACIÓN EXPLÍCITA

En "Estados, transitividad y clíticos..." -apartado centrado en la hipótesis aspectual (cf. supra)- hemos podido comprobar cómo la práctica totalidad de las propuestas -incluidas aquellas que aluden explícitamente a los estados- insisten en cierta dependencia unilateral entre el clítico no reflexivo concordado con el sujeto en las construcciones transitivas y la determinación del sustantivo núcleo del SN que ejerce de OD: el primero exige la presencia de la segunda. Detengámonos en primer lugar, por tanto, en ejemplos con predicados estativos en los que tal determinación se encuentra presente.

Si se contrasta (1) ("El alumno se supo la lección"), (23a) ("Muchos ciudadanos se creen esos bulos [sobre todo tipo de asuntos]") y (29) ("Mario se cree las historias que le cuentan"), por un lado, y (2) ("Juan [*se] posee los discos de su padre"), (16) ("Juan [*se] odia las acelgas") y (17) ("Juan [*se] quiere a Elena"), por otro, resulta evidente la gramaticalidad del primer grupo de ejemplos en oposición a la agramaticalidad de los del segundo. La revisión crítica que hemos hecho en "Estados, transitividad y clíticos..." de las propuestas de autores que se 
han ocupado de la compatibilidad de este clítico con los estados en las construcciones transitivas no nos ha permitido encontrar una explicación convincente de esta disparidad de comportamiento de los predicados estativos, cuya clave, desde nuestro punto de vista, puede residir en si el estado denotado se concibe o no al margen de unas determinadas circunstancias espaciotemporales. Recurrimos en este sentido a la diferencia que Carlson (1977) establece, se trate de eventos o no, entre predicados episódicos -inmersos en circunstancias espaciotemporales concretas, esto es, suceden o se dan en ocasiones, pues poseen un carácter transitorio- y predicados individuales -no inmersos en ese tipo de circunstancias, es decir, no suceden o se dan en ocasiones, ya que carecen de carácter transitorio ${ }^{29}$. Como prueba para identificar estos tipos de predicados en español, Laca (1999, p. 905, n. 7) señala que los predicados episódicos pueden aparecer con nombres propios o con sintagmas demostrativos como argumentos en una subordinada introducida por siempre que, cada vez que..., mientras que los predicados individuales carecen de esta posibilidad. Los primeros admiten repeticiones distintas en el espacio y/o en el tiempo con los mismos participantes, pero no los segundos. Así, en tanto que saber y creer, con los significados léxicos particulares que presentan en (1), (23a) y (29), son predicados episódicos, odiar, poseer y que$r e r$, tal y como aparecen en (2), (16) y (17), se presentan como predicados individuales:

${ }^{29}$ La distinción de CARLSON (1977) entre stage-level predicates ('predicados episódicos') e individual-level predicates ('predicados individuales') equivale a la diferencia que DowTy (1979) propone entre momentary predicates e interval predicates; a la de BACH (1986) entre dynamic states y static states; a la de KupFERMAN (1991) entre prédication événementielle y prédication nonévénementielle, a la de KRIFKA et al. (1995) entre non-dispositional predicates y dispositional predicates; a la de BERTINETTO (1997) entre contingent y permanent; a la de Marín (2000) entre acotados y no acotados; a la de CunHa (2004) entre estados de individuo y estados de estadio, etc. Cuartero Otal (2007, pp. 119120) y Cuartero Otal y Horno Chéliz (2012, p. 99) proponen incluir esta diferencia, más que en el ámbito del léxico, en el de los enunciados. Silvagni (2017, pp. 86 ss. y 2018, pp. 34-37) plantea la dicotomía predicados episódicos-predicados individuales no como una distinción fundamentada en criterios del tipo transitoriedad/ permanencia, sino como un contraste aspectual que distingue, en primer lugar, entre predicados eventivos -los episódicos, que aluden a un punto espaciotemporal o estadio- y no eventivos -los individuales, desprovistos de un punto espaciotemporal, pues aluden a propiedades de entidades. Posteriormente, sólo en el ámbito de los eventivos, se diferencia entre predicados dinámicos y no dinámicos. 
(32) a. $\{$ Siempre que/ Cada vez que $\}$ este alumno sabe la lección...

b. \{Siempre que/ Cada vez que $\}$ Mario cree las historias que le cuentan...

c. $\{$ Siempre que/ Cada vez que $\}$ estos ciudadanos creen esos bulos...

(33) a. *\{Siempre que/ Cada vez que $\}$ Juan odia las acelgas...

b. *\{Siempre que/ Cada vez que $\}$ Juan posee los discos de su padre...

c. * $\{$ Siempre que/ Cada vez que $\}$ Juan quiere a Elena...

Por tanto, cuando se trata de estados que son predicados episódicos -que en una propuesta como la de Silvagni (2017 y 2018) (cf. n. 29), más que como estados, deberían calificarse como eventos no dinámicos-, el clítico tiene la opción de aparecer (cf. 1, 23a y 29), pero no si el estado es un predicado individual (cf. 2,16 y 17 ).

Ahora bien, conviene hacer alguna observación a lo dicho, como advertir de la diferencia de comportamiento que conforme a este criterio pueden presentar verbos homónimos. Así, por ejemplo, frente al saber de (1) -con un significado análogo a "estar instruido en algo"-, existe otro con un significado análogo a "tener noticia o conocimiento de algo" que no es compatible con el clítico en estructuras transitivas, pues carece de valor episódico:

(34) a. Pedro (*se) sabe que Luis va a llegar mañana.

b. *\{Siempre que/ Cada vez que $\}$ Pedro sabe que Luis va a llegar mañana...

No obstante, ocurre que si en (34a), en la subordinada que funciona como OD, se elide el adjunto circunstancial mañana o se sustituye por otro cuya naturaleza deíctica señala un punto temporal, pero no en relación con el momento de la enunciación, sino con otro distinto, la construcción sigue siendo incompatible con el clítico, pero la estructura introducida por \{siempre que/ cada vez que\} sí parece posible:

(35) a. Pedro (*se) sabe que Luis va a llegar (al día siguiente).

b. $\{$ Siempre que/Cada vez que $\}$ Pedro sabe que Luis va a llegar (al día siguiente)... 
La aceptabilidad de $(35 b)$, pensamos, reside en que el OD de saberalude a un evento. Si en la subordinada que lo representa no hay indicación que permita situarlo temporalmente, en (35b) se entenderá que, cada vez que el estado de saber se repite, se trata no del mismo evento en el que Luis va a llegar a algún lugar, sino de eventos diferentes, aunque Luis y el lugar tengan en todos los casos el mismo referente. Si en la subordinada se hace explícita una indicación temporal como al día siguiente, el momento con respecto al cual esta indicación sitúa temporalmente el evento denotado se muestra enormemente diverso ("al día siguiente de que le den las vacaciones", “...de que le paguen", etc.) y ello conduce, nuevamente, a que en (35b), cada vez que el estado de saber se repite, el evento al que alude la subordinada sea en cada caso un evento distinto. Por consiguiente, el hecho de que el estado denotado en la versión sin el clítico de (34a) no pueda repetirse en circunstancias espaciotemporales distintas con idénticos participantes -en cada caso el evento de llegar sería diferente- justifica de alguna manera la incompatibilidad del clítico en (34a). Mutatis mutandis, algo análogo sucede si se contrasta (33b) con (36):

(36) \{Siempre que/Cada vez que\} Juan posee un gran número de discos...

Cabría justificar ahora la gramaticalidad de (36) a partir del valor no específico del OD (un gran número de discos), pues, en este caso, cada vez que el estado al que alude poseer se repite, se trata de discos diferentes y no de los mismos, esto es, el estado de poseer un gran número de discos se puede reiterar en circunstancias espaciotemporales distintas, pero siempre con participantes diferentes. El hecho de que el estado denotado en un ejemplo como la versión sin el clítico de (37) no pueda repetirse en circunstancias espaciotemporales distintas con idénticos participantes justifica de alguna manera la incompatibilidad del clítico:

(37) Juan (*se) posee un gran número de discos.

Prestemos ahora atención a ejemplos con predicados estativos y episódicos cuyos OD presentan un plural escueto, esto es, un SN con un sustantivo plural sin determinación. En este sentido, en tanto que la agramaticalidad de (3) ("*El alumno 
se supo lecciones") resulta evidente, ejemplos del tipo de (4) ("Los ciudadanos se temen represalias por parte del Gobierno)", (22) ("Juan se merecía aplausos y no silbidos") y (23b) ("Muchos ciudadanos se creen bulos * [sobre todo tipo de asuntos]") -este último en su versión con la secuencia sobre todo tipo de asuntos explícita- se muestran como perfectamente aceptables. Si, en primer lugar, comparamos (3) con (38), parece evidente que, al menos cuando se trata de nombres comunes, a falta de un determinante en el SN que ejerce de OD, el único requisito para que la aparición del clítico se haga posible es la presencia de complementación nominal en este $\mathrm{SN}^{30}$ :

(38) El alumno se supo lecciones * (que nadie antes se había sabido).

La idea se refuerza al contrastar (23b) con (23a) ("Muchos ciudadanos se creen esos bulos [sobre todo tipo de asuntos]"). Ahora bien, nuestra intención no es plantear que los complementos en los plurales escuetos presentan un carácter determinativo. Dice Bosque (1996, p. 80) que en casos como éstos los complementos restringen la denotación de los sustantivos de forma parecida a como un demostrativo especifica y restringe el ámbito de entidades de las que se predica un nombre común. Frente a ello, partimos de la idea de que la determinación no modifica las posibilidades designativas del sustantivo, sino que las realiza, esto es, permite pasar de la designación potencial que tiene ese sustantivo en el sistema de la lengua a una designación real o denotación en el hablar concreto ${ }^{31}$. La complementación nominal, por su parte, sí modifica las posibilidades designativas del sustantivo y su denotación (cf. n. 30) ${ }^{32}$. Así, en

30 Por complementación nominal-modificación nominal para algunos autores (cf. RigAu 1999)- entendemos 'cualquier operación que sirva para modificar las posibilidades designativas del sustantivo y su denotación’ (cf. Coseriu 1967a, p. 304).

${ }^{31}$ El hablar, entendido como actividad, equivale, en lo universal, a la 'actividad lingüística concreta', considerada en general. En lo particular, equivale al discurso de un individuo en una oportunidad concreta. Y en lo histórico, a un modo de hablar propio de una comunidad, es decir, a una lengua concreta (cf. Coseriu 1967a, p. 286).

${ }^{32}$ La designación, al menos de forma genérica, equivale a la realidad extralingüística y a su papel en la actividad del lenguaje (cf. CosERIU 1981b, pp. 187-189; 1978, p. 207; 1978a, p. 117; y 1978b, p. 135). A la designación opone Coseriu (1981b, p. 187) el significado, entendido como 'el contenido 
tanto que, por ejemplo, el determinante que acompaña a lección en (1) ("El alumno se supo la lección") convierte la designación potencial de éste en denotación y orienta ésta hacia un ente particular -de ahí el carácter específico y delimitado del SN completo-, lo que hace el complemento de lecciones en (38) es restringir esta denotación estableciendo la clase de las lecciones que nadie antes se había sabido dentro de la clase de las lecciones $^{33}$. La ausencia de determinante impide asignar carácter específico y delimitado al SN completo.

Sin embargo, tanto (4) ("Los ciudadanos se temen represalias por parte del Gobierno") como (22) ("Juan se merecía aplausos y no silbidos") -ambos con predicados claramente episódicos- podrían presentarse como contraargumentos a la generalización de la hipótesis defendida en el párrafo anterior en todos los casos. En (4), el complemento de represalias podría elidirse y la presencia del clítico mantendría la gramaticalidad de la oración:

(39) Los ciudadanos se temen represalias.

En (22), el sustantivo aplausos aparece directamente sin complementación nominal alguna. Sin embargo, desde nuestro punto de vista, (22) y (39) no dejan de ser casos excepcionales a cuyas explicaciones, en realidad, subyace la idea general de que en estas estructuras transitivas la aparición del clítico sólo se hace posible si el OD, cuando presenta un nombre común,

de un signo o de una construcción en cuanto dado por la lengua misma'. La designación virtual equivale a la potencialidad de aludir a los objetos, frente a la designación real o denotación, que se identifica con la alusión a los objetos concretos (cf. Coseriu 1967a, p. 294). Acerca de las interpretaciones del término designación, cf. Casas Gómez (1999, pp. 61-63 y 2002, pp. 55 ss.).

${ }^{33}$ Acerca de conceptos como actualización -al que volveremos más adelante (cf. n. 40)-, discriminación -y sus tipos: cuantificación, selección, situación-, delimitación -y sus tipos: especificación, explicación, especialización- e identificación aplicados a la determinación y complementación nominal, cf. CosERIU 1967a, pp. 293-308. Según esta propuesta, no sería adecuado caracterizar los demostrativos como elementos que restringen la denotación de los sustantivos a los que determinan, sino como discriminadores -orientan la denotación hacia un ente o grupo de entes particulares- y, al mismo tiempo, situadores -sitúan los entes denotados con respecto a las personas y circunstancias implicadas en el discurso (cf. Coseriu 1967a, p. 301). 
muestra determinante o si se trata de un plural escueto con complementación nominal.

Para explicar (22), pensamos, no sería adecuado recurrir a la idea de que se trata de un ejemplo en el que la negación correctiva que representa la secuencia y no silbidos permite enfatizar aplausos y presentarlo como foco contrastivo o refutativo en la estructura informativa de la oración ${ }^{34}$. La razón es que esta focalización no es compatible con otros estados con el clítico en los que el OD carece de determinación y complementación nominal:

(40) $a$. *El alumno se supo lecciones y no tonterías.

b. *Muchos ciudadanos se creen bulos y no realidades.

Tampoco sería correcto pensar que la explicación de por qué aplausos aparece en (22) como plural escueto sin complementación estriba en que, frente a lecciones y bulos, es un sustantivo deverbal al que acompaña, por serlo, una estructura argumental propia y en que, por tanto, aunque no se haga explícito en el discurso, se entiende que los aplausos provienen siempre de alguien, o sea, que hay una complementación nominal implícita. Esta objeción queda justificada pues, en tanto que (22) seguiría siendo gramatical sin la secuencia que expresa la negación correctiva, no sucede lo mismo con otros sustantivos igualmente deverbales:

(41) Juan se merecía \{aplausos/*castigos\}.

Quizás la solución del enigma pueda hallarse en las características semánticas de estos sustantivos. Como se sabe, los grupos nominales sin determinante que son plurales escuetos no aluden a entidades específicas, sino a tipos de entidades (cf. Condoravdi 1987; Bosque 1996, pp. 24-25; Laca 1996, pp. 242 ss.; Garrido 1996, pp. 302 ss.). Sin embargo, pensamos, no tiene por qué ser siempre así. Y ello va a depender de los ras-

34 Acerca del foco, entendido como 'constituyente máximo al que se etiqueta como información nueva o no presupuesta', cf., entre otros, CHомsкY 1972, pp. 90-91 y 1976; JaGKENDOFF 1972; SElKirk 1984; ZubizarReta 1998, pp. 1-7 y 1999, pp. 4224 ss.; BosQue y GutiérRez-ReXach 2009, pp. 678 ss., etc. Sobre la dicotomía "foco neutro o informativo-foco contrastivo" aplicada a estructuras sintácticas del español, cf. ZubizarReta 1998, pp. 6-7 y 1999, p. 4228, y Bosque y GutiérReZ-ReXach 2009, p. 682. 
gos semánticos de los sustantivos. En este sentido, la diferencia entre aplauso y castigo es que el primero posee cierto valor colectivo del que carece el segundo: aplauso en singular alude a un conjunto homogéneo y unitario de entidades (conjunto de golpes dados con las manos); castigo en singular no equivale a conjunto homogéneo y unitario de entidades alguno. Aplausos en plural puede referirse a un conjunto con varios subconjuntos homogéneos y unitarios de este tipo de palmoteo (varias acciones distintas en las que se palmotea) o a uno solo de esos subconjuntos (una sola acción de palmotear por parte de una o más personas). En el primer caso estaríamos ante el plural de un sustantivo contable y cuantificable mediante cuantificadores que permiten establecer cómputos (\{tres/varios $\}$ aplausos). En el segundo, se trataría de un plural meramente estilístico. Así, pues, decir de alguien que merece $\{$ un/ el $\}$ aplauso o $\{$ unos/los $\}$ aplausos puede significar en ambos casos que esa persona merece un solo conjunto homogéneo y unitario de golpes dados con las manos por parte de otros. Por tanto, cuando este sustantivo aparece como plural escueto en (41), ese plural puede tener un mero valor estilístico y, entonces, en vez de aludir a tipos de entidades de una misma clase, como habitualmente hacen los plurales escuetos, se refiere a un solo conjunto homogéneo, unitario y no específico de entidades, tal como sucede con un aplauso en $(42)^{35}$ :

(42) Juan se merecía un aplauso.

Es esta identidad referencial con un SN con determinante, pensamos, la que explica que, excepcionalmente, aparezca un plural escueto sin complementación nominal como OD en (22) ("Juan se merecía aplausos y no silbidos") y (41).

De manera análoga, es el carácter inherente o de pluralia tantum del plural represalias el que explica la gramaticalidad,

35 Acerca de la posibilidad de establecer la distinción "específico-inespecífico", tanto en el ámbito de los grupos nominales introducidos por el artículo determinado como en el de los introducidos por el artículo indeterminado, cf. Leonetti 1999, pp. 791 ss. Así, mientras que la referencia de un aplauso en (42) se hace a un conjunto homogéneo, unitario y no específico de entidades, esto es, a un aplauso no identificable o concreto, en (i) se hace a un referente identificable o concreto, es decir, a una referencia específica: (i) "En estos momentos escucho un aplauso". 
junto a (4) ("Los ciudadanos se temen represalias por parte del Gobierno"), de (43):

(43) Los ciudadanos se temen represalias.

Como se sabe, al igual que los plurales estilísticos, los plurales inherentes no muestran diferencias designativas con respecto a sus poco frecuentes singulares (cf. Ambadiang 1999, p. 4886). Así, la referencia de represalias en (43) no se diferencia de la de un SN con determinante como alguna represalia en (44):

(44) Los ciudadanos se temen alguna represalia.

Ambos SN aluden a un solo conjunto inespecífico de acciones de castigo.

Lo dicho hasta aquí no significa que los únicos OD sin determinación nominal que pueden aparecer en predicaciones estativas episódicas transitivas con un clítico no reflexivo concordado con el sujeto sean los plurales escuetos con complementación o los plurales escuetos sin complementación pero con valor estilístico o inherente. Cabe la posibilidad de que haya construcciones de este tipo en las que, si la restricción seleccional del verbo lo permite ${ }^{36}$, el OD esté representado por un nombre propio o por una forma pronominal tónica (cf. 5: "[Nos] creemos $\{$ a Juan/ a éste/ a éstos/ eso/ todo $\})^{37}$. En estos casos, además de explicar el contraste de gramaticalidad entre (5) y, por ejemplo, (17) ("Juan [*se] quiere a Elena") mediante el criterio que hemos establecido, el cual contrapone (33c) ("*\{Siempre que/ Cada vez que\} Juan quiere a Elena...") a (45),

36 Diferencias relativas a la restricción seleccional de los verbos explican el contraste entre (4) ("Los ciudadanos se temen represalias por parte del Gobierno") y (i) “*Los ciudadanos se temen a Mariano”. En tanto que en (4) temer es un verbo con un significado léxico análogo a creer, con valor de predicado episódico, en (i) es un verbo con significado léxico análogo a 'sentir temor', con valor de predicado individual: (ii) "\{Siempre que/ Cada vez que\} estos ciudadanos temen represalias por parte del Gobierno..."; (iii) "*\{Siempre que/ Cada vez que $\}$ estos ciudadanos temen a Mariano...".

37 En los casos en que el OD está representado por una forma átona del pronombre personal no es posible hacer uso del leísmo (cf. MACDonaLd 2017). Obsérvese, en este sentido, el contraste entre (i) y (ii): (i) " $\{\mathrm{Lo} / \mathrm{Le}\}$ creemos"; (ii) "Nos $\{1 \mathrm{lo} * \mathrm{le}\}$ creemos". 
(45) $\{$ Siempre que/Cada vez que $\}$ creemos $\{$ a Juan/a éstos/ eso/ todo\}...,

conviene advertir las diferencias que se observan si se compara (5) con el grupo que conforman (1) ("El alumno se supo la lección"), (3) ("*El alumno se supo lecciones") y (38) (El alumno se supo lecciones * [que nadie antes se había sabido]"). Tal como muestran los tres últimos ejemplos, el nombre común lección exige la presencia del determinante o de la complementación nominal para que el clítico sea compatible, pero no sucede lo mismo con el nombre propio Juan o con las formas pronominales tónicas que ejercen de OD en (5). En lo que atañe a la versión de (5) con el nombre propio ${ }^{38}$, cabe plantear que este tipo de nombres, frente a los comunes, no necesita determinante para poder referirse a la realidad -para denotar (cf. n. 32)- debido a su carácter monovalencial. Los nombres propios no se emplean con el mismo valor semántico para objetos diferentes, como sucede con la mayoría de los comunes, sino que se emplean, o bien para un solo ente individual (Dinamarca), o bien para individuos diferentes, aunque no con la misma, sino con distinta intensión (Juan $)^{39}$. Los entes a los que se aplica un mismo nombre propio no constituyen una extensión correspondiente a una misma intensión, sino que cada uno de ellos forma por sí solo una extensión separada que corresponde a una intensión separada y distinta. El nombre Juan, por ejemplo, no supone una extensión que comprende a todos los individuos que se llaman Juan, sino que, cada vez que empleamos este nombre para aludir a individuos distintos, se

38 Esta versión de (5) rebate la propuesta de Pena (1982, p. 239) y Narbona (1984, p. 181) acerca de que no es posible emplear este tipo de construcción con OD animados y la de D'InTRONo et al. (2007, p. 13), para quienes en estos casos el OD no puede ser un nombre propio. MARTín ZORRAQUINO (1979, p. 106) ofrece más ejemplos en contra del razonamiento de los dos primeros autores.

39 Obviamente, esto no significa que todo nombre común sea plurivalente, es decir, nombre de clase, ni que todo nombre común posea significado léxico. Entre los nombres comunes no plurivalentes se encuentran, por ejemplo, los no contables, que, aun con significado léxico, denotan objetos extensos (agua; cf. Devís Márouez 2009, pp. 469 y 472) o los términos que simplemente designan objetos únicos (metro). Los sustantivos con carácter estrictamente terminológico, incluso cuando son nombres de clase (átomo), carecen de significado léxico (cf. Coseriu 1981, pp. 95-96; 1981a, pp. 291292, y 1987; y Devís Márouez 2009, pp. 472-473). 
trata de "extensiones individuales", distintas en cada caso (cf. Coseriu 1967, pp. 267-269).

Que los nombres propios carezcan de significado léxico, que su designación virtual coincida siempre con su denotación y que su denotación sea siempre individual los exime de ir acompañados por un determinante no sólo para denotar meramente entes o individuos de la realidad extralingüística -tanto es así que algún autor advierte que los nombres propios son de por sí actuales, es decir, están orientados por sí solos hacia el ámbito de los objetos y los individuos (cf. Coseriu 1967a, p. 295, y 1981, p. 128) ${ }^{40}$, sino también, por ejemplo, para orientar esa denotación hacia un ente o individuo particular o grupo de entes o individuos particulares, esto es, para discriminar la denotación (cf. n. 32 y n. 33). Efectivamente, un nombre común con significado léxico puede simplemente denotar y no orientar esa denotación hacia uno o más entes particulares. Es lo que sucede cuando, precedido por un determinante, alude a un ente genérico o no discriminado ("El hombre es mortal"). Pero mediante la determinación también puede, a la vez que denotar, orientar su denotación y referirse a un ente particular o a un grupo de entes particulares (" $\mathrm{El}$ hombre/Los hombres\} \{vino/vinieron\} ayer a mi casa"). El grupo nominal en el que se incluye puede quedar dotado de este modo de una interpretación definida y específica. Frente a los nombres comunes, los propios, caracterizados por llevar incorporada una denotación individual, no necesitan de la determinación para denotar ni para orientar la denotación. Tanto es así que algún estudioso cataloga el nombre propio en su uso prototípico referencial como una categoría sintácticamente autodeterminada, esto es, como un SD con determinación definida y específica (cf. Longobardi 1994, pp. 621 ss., y Fernández Leborans 1999, p. 103, n. 49). Ello explica estructuras como la que muestra la versión de (5) con el nombre propio.

40 El concepto de actualización, tal y como lo expone BALLY (1965, pp. 77 ss.) en la tradición europea, ha sido tachado de vago e impreciso (cf. BosQue 1996, pp. 15-16, n. 3). En nuestro caso, aludimos a la actualización en el sentido que plantea Coseriu (1967a, pp. 293-297), para quien, frente a BALLY, ésta no identifica lo lingüístico con lo extralingüístico, sino que únicamente lo pone en relación, la cual se revela en la denotación. Además, para Coseriu, la actualización difiere de otro tipo de operaciones con el que BALly la hace coincidir; tal es el caso de la individualización, la localización y la cuantificación (cf. supra, n. 33). 
Ahora bien, que los nombres propios estén exentos de la necesidad de ir acompañados por determinantes para denotar y orientar la denotación no significa que no puedan admitir este acompañamiento, aunque ello sucede sólo cuando modifican su designación virtual para usarse como nombres plurivalentes, es decir, como nombres de clase. Así, en Devís Márquez (2009, pp. 475-476) se plantea que decir, por ejemplo, $\{u n / d o s\}$ Juan(es) o \{muchos/ pocos\} Juanes no alude a miembros distintos de una clase de individuos denominada "Juan" que se haya elaborado a priori por un grupo social. Estos ejemplos se explican por la posibilidad que tienen los hablantes de idear, en su actividad lingüística de hablar (cf. n. 31), clases con el conjunto de individuos que poseen nombres propios formalmente idénticos. No se trata ya de una clase elaborada a priori por una comunidad lingüística o por un grupo científico o social -como las terminologías, cf. Coseriu 1981, pp. 95-96; 1981a, pp. 291-292; y 1987-, sino de una clase establecida individualmente por un hablante concreto en un acto de hablar concreto. Frente a lo que ocurre con las clases denotadas por los nombres comunes, se trata de una clase cuyo origen se encuentra en el mismo nombre propio. La discriminación que llevan a cabo unidades como un, dos, muchos, pocos en estos ejemplos no ocurre en la denotación individual primaria del nombre Juan, sino en otra denotación secundaria resultado de la creación por parte del hablante de una nueva designación potencial para el nombre Juan ('individuo con la característica de llamarse Juan'). Lo que hace el hablante en el hablar es convertir Juan en un nombre plurivalente, aunque sin significado léxico, que pueda utilizarse con una misma designación, no con distintas, para aludir a diversos individuos. Sin embargo, esa plurivalencia pertenece en estos ejemplos exclusivamente al ámbito del hablar, del discurso, pues es resultado de la determinación nominal y no de la naturaleza del nombre Juan, el cual, precisamente por su naturaleza, conserva su condición de nombre monovalente en el sistema de la lengua española ${ }^{41}$.

41 Acerca de la posibilidad de que el nombre propio aluda a clases diferentes de aquellas a las que el nombre común puede referirse, cf. también Coseriu 1967, p. 278; Bloomfield 1976, p. 205; Gary-Prieur 1994, pp. 98-104; Fernández Leborans 1999, p. 115, n. 77. Sobre los distintos valores que puede adquirir la determinación y la complementación del nombre propio, cf. Devís Márouez 2009, pp. 477 ss. 
De lo dicho en el párrafo inmediatamente anterior cabe inferir, pues, la posibilidad de que haya construcciones transitivas con predicados estativos y un clítico no reflexivo concordado en número y persona con el sujeto en las que el OD sea un nombre propio con un determinante que discrimina su denotación secundaria, no la primaria, que sigue siendo individual:

(46) Nos creímos a \{un/ dos/ muchos/ pocos\} Juan(es).

Adviértase en este sentido la imposibilidad de la construcción con el nombre propio en plural si éste no ha abandonado su denotación primaria mediante la presencia de un determinante:

(47) *Nos creímos a Juanes.

En lo que respecta a la versión de (5) (“[Nos] creemos \{a Juan/ a éste/ a éstos/ eso/ todo\}") con las formas pronominales tónicas ejerciendo de OD, resulta evidente que todas ellas equivalen a grupos nominales con determinante $-\mathrm{O}$ a grupos con nombres propios, ya de por sí actualizados en el sentido coseriano del término- y carecen de la interpretación de tipo, característica de los plurales escuetos. Estos últimos no aluden a conjuntos de entidades o individuos, como sí hacen los grupos nominales con determinante, ni a individuos, como sí hacen los grupos nominales con nombres propios, sino, ya lo hemos advertido, a tipos de entidades o individuos de una misma clase. Tanto es así que en (48a) el OD es siempre sustituible por una forma pronominal tónica, como muestra (48b), mientras que en (49a) tal posibilidad es inexistente, según muestra $(49 b)$ :

(48) a. Creyeron \{a Juan/ a los profesores/los bulos\}.

b. Creyeron $\{$ a éste/ a éstos/ eso/todo\}.

(49) a. Creyeron \{a profesores/ bulos\}.

b. Creyeron \{\#a éstos/\# \#so/\#todo\}.

A modo de conclusión, tres ideas básicas pueden inferirse de todo lo dicho en este apartado. Primera: los predicados estativos son compatibles en las estructuras oracionales transitivas con un clítico no reflexivo concordado con el sujeto siempre que muestran un carácter episódico, pero no cuando ese carác- 
ter es individual. Segunda: los predicados estativos episódicos en este tipo de estructuras oracionales, frente a lo postulado por la hipótesis aspectual, admiten también OD que son plurales escuetos, aunque sólo si el sustantivo en plural se encuentra complementado. Excepcionalmente, pueden hacerlo del mismo modo cuando se trata de OD que son plurales escuetos sin complementación y presentan un valor estilístico o inherente. Tercera: cabe igualmente la posibilidad de que este tipo de construcciones presente OD, en singular o en plural, que no son plurales escuetos y que carecen de determinación explícita. Sucede esto, bien cuando el sustantivo que ejerce de OD es intrínsecamente determinado, caso de los nombres propios con denotación primaria, bien cuando el OD se encuentra representado por una forma pronominal tónica equivalente a un grupo nominal con determinación, sea ésta explícita o implícita.

\section{CONCLUSIONES FinAlES Y GUESTIONES NO RESUELTAS}

Hemos advertido de los problemas que presentan tanto la hipótesis aspectual como las que se centran en la implicación del sujeto y de la relación sujeto-OD para explicar: 1) que algunos predicados estativos coincidan con algunos predicados eventivos (realizaciones, actividades y logros) en que son compatibles con un clítico no reflexivo concordado con el sujeto en estructuras oracionales transitivas; 2) la compatibilidad de unos predicados estativos con este clítico en este tipo de estructuras frente a la incompatibilidad de otros; 3) la compatibilidad de determinados predicados estativos con este clítico en este tipo de estructuras con algunos OD que son plurales escuetos; 4) la compatibilidad de determinados predicados estativos con este clítico en este tipo de construcciones con OD que no son plurales escuetos y carecen de determinación explícita.

Si bien a lo largo del artículo hemos corroborado la coincidencia referida entre predicados estativos y predicados eventivos -también la dificultad que entraña el propio concepto de estado-, hemos elaborado una hipótesis que sólo intenta dar explicación a los tres últimos problemas citados en el párrafo anterior: la presencia del clítico con los estados se restringe a los predicados episódicos; la necesidad, salvo excepciones puntuales, de la complementación nominal con los plurales escuetos de nombres comunes que funcionan como OD y la posibilidad 
del clítico con OD carentes de determinación explícita y complementación nominal cuando se trata de nombres propios y pronombres. Queda por completar nuestra propuesta evidenciando las razones de tal coincidencia, es decir, respondiendo a si existe un valor común del clítico en todos estos casos que justifique su presencia. Posteriormente, sería importante responder, por un lado, a si las posibilidades de determinación y complementación que hemos asignado a los sintagmas que funcionan como OD en estas estructuras con clítico y predicados estativos son extrapolables a las construcciones con clítico y predicados eventivos; por otro, a si esas posibilidades de determinación y complementación muestran alguna relación con el valor del clítico. Tal como advertimos supra, p. 4, tratamos todos estos asuntos en un trabajo prácticamente concluido y próximo a publicarse.

\section{REFERENCIAS}

Alarcos Llorach, Emilio 1980. "Valores de /se/", en Estudios de gramática funcional del español, $3^{\mathrm{a}}$ ed., Gredos, Madrid, pp. 213-222.

Alcina Franch, Juan y J. Manuel Blecua 1983. Gramática española, $4^{\mathrm{a}}$ ed., Ariel, Barcelona.

Alonso Cortés, Narciso 1939. El pronombre "se" y la voz pasiva castellana, Artes Gráficas, Valladolid.

Ambadiang, Théophile 1999. "La flexión nominal. Género y número”, en Gramática descriptiva de la lengua española. Dirs. Ignacio Bosque y Violeta Demonte, Espasa, Madrid, t. 3, pp. 4843-4913.

Amstrong, Grant 2013. "Agentive reflexive clitics and transitive se constructions in Spanish”, Borealis: An International Journal of Hispanic Linguistics, 2, 2, pp. 81-128, doi: https://doi.org/10.7557/1.2.2.2526.

Arce Arenales, Manuel A. 1989. Semantic structure and syntactic function. The case of Spanish "se", University of Colorado at Boulder, https:/ /www. researchgate.net/ publication/ 36054293_Semantic_structure_and_syntactic_function_the_case_of_Spanish_se [consultado el 12 de julio de 2018].

Arce Arenales, Manuel A. 1994. "Un esquema formal para una interpretación funcionalista de las construcciones con se en español”, Filología y Lingüistica, 20, 2, pp. 193-213, doi: 10.15517/RFL.V20I2.20257.

Azpiazu, Susana 2004. "Reflexiones en torno al clítico se en español", Estudios de Lingüistica. Universidad de Alicante, 18, pp. 7-20, doi: 10.14198/ ELUA2004.18.01.

BABcock, SANDRA S. 1970. The syntax of Spanish reflexive verbs. The parameters of the middle voice, Mouton, The Hague.

BACH, EMmon 1986. "The algebra of events", Linguistics and Philosophy, 9, pp. 5-16, doi: 10.1007/BF00627432. 
Bally, Charles 1965. Linguistique générale et linguistique française, $4^{\mathrm{a}}$ ed., Éditions Francke, Bern.

BARra Jover, Mario 1996. "Dativo de interés, dativo aspectual y las marcas de aspecto perfectivo en español”, Verba, 23, pp. 121-146, http:// hdl. handle.net/ 10347 / 3268.

Basilico, David 2010. "The seclitic and its relationship to paths", Probus, 22, pp. 271-302, doi: https://doi.org/10.1515/prbs.2010.010.

Bello, Andrés (y Rufino J. Cuervo) 1964 [1860]. Gramática de la lengua castellana, $7^{\mathrm{a}}$ ed., Sopena Argentina, Buenos Aires.

Benavides, Carlos 2010. "El clítico se en español y la estructura léxico-conceptual”, Rilce, 26, 2, pp. 261-288.

Bertinetto, Pier M. 1997. Il dominio tempo-aspettuale. Demarcazioni, intersezioni, contrasti, Rosenberg \& Sellier, Torino.

Bloomfield, LeOnARD 1976. Language, G. Allen \& Unwin, London.

Bogard, Sergio 2000. "El clítico reflexivo como marcador aspectual en español", Tópicos del Seminario, 3: Aspectualidad y modalidades, pp. 37-52.

Bogard, Sergio 2006. "El clítico se. Valores y evolución”, en Sintaxis histórica de la lengua española. Primera parte: La frase verbal. Dir. Concepción Company, Universidad Nacional Autónoma de México-Fondo de Cultura Económica, México, t. 2, pp. 753-870.

Bogard, Sergio 2009. "Actividad, atelicidad y «pseudo-objeto» en español”, Nueva Revista de Filología Hispánica, 57, 1, pp. 1-35, doi: http://dx.doi. org/10.24201/nrfh.v57i1.2397.

Bogard, Sergio 2015. "Los clíticos pronominales del español. Estructura y función”, Nueva Revista de Filología Hispánica, 63, 1, pp. 1-38, doi: http:// dx.doi.org/ 10.24201/ nrfh.v63i1.1189.

Bosque, IgNacio 1996. "Por qué determinados sustantivos no son sustantivos determinados. Repaso y balance", en El sustantivo sin determinación. La ausencia del determinante en la lengua española. Ed. Ignacio Bosque, Visor, Madrid, pp. 13-119.

Bosque, Ignacio y Javier Gutiérrez-Rexach 2009. Fundamentos de sintaxis formal, Akal, Madrid.

Bull, William E. 1952. "The intransitive reflexive: ir and irse", The Modern Language Journal, 36, 8, pp. 382-386, doi: https://doi.org/10.1111/ j.1540-4781.1952.tb06587.

Camacho Ramírez, Rafael M. 2014. El clítico "se" aspectual y causa, Universidade Estadual de Campinas, https:/ /www.espanolavanzado.com/ images/pdfs/ se_aspectual_causa.pdf [consultado el 12 de julio de 2018].

Camacho Ramírez, Rafael M. 2014a. "El se aspectual y causa en español de Lima”, Cuadernos de Estudios Lingüisticos, 56, 1, pp. 115-139, doi: 10.20396/cel.v56i1.8636527.

Campanini, Cinzia \& Florian Schäfer 2011. Optional se-constructions in Romance: Syntactic encoding of conceptual information, documento en Generative Linguistics in the Old World 34, Universität Wien, http:/ / amor.cms. hu-berlin.de/ schaeffl/papers/glow34.pdf [consultado el 12 de julio de 2018].

Cano Aguilar, Rafael 1981. Estructuras sintácticas transitivas en el español actual, Gredos, Madrid. 
Carlson, Greg N. 1977. "A unified analysis of the English bare plural”, Linguistics and Philosophy, 1, pp. 413-457, doi: https://doi.org/10.1007/ BF00353456.

Cartagena, Nelson 1972. Sentido y estructura de las construcciones pronominales en español, Publicaciones del Instituto Central de Lenguas de la Universidad de Concepción, Concepción.

Casas Gómez, Miguel 1999. Las relaciones léxicas, Niemeyer, Tübingen.

Casas Gómez, Miguel 2002. Los niveles del significar, Servicio de Publicaciones de la Universidad de Cádiz, Cádiz.

Сномsкy, Noam 1972. "Deep structure, surface structure and semantic interpretation", en Studies on semantics in generative grammar, Mouton, The Hague, pp. 62-119.

Сномsкy, Noam 1976. "Conditions on rules of grammar", Linguistic Analysis, 2, pp. 303-352.

Сномsкy, Noam 1986. Knowledge of language. Its nature, origin and use, Praeger, New York.

Comrie, Bernard 1976. Aspect. An introduction to the study of verbal aspect and related problems, Cambridge University Press, Cambridge.

Condoravdi, Cleo 1987. "Arbitrary reference, pro and bare plurals", Papers from the 23 Regional Meeting of the Chicago Linguistic Society, 23, pp. 18-30.

Contreras, Lidia 1966. "Significados y funciones del se", Zeitschrift für Romanische Philologie, 82, 3/4, pp. 298-307.

Coseriu, Eugenio 1967. "El plural de los nombres propios", en Teoría del lenguaje y lingüistica general, $2^{\mathrm{a}}$ ed., Gredos, Madrid, pp. 261-281.

Coseriu, Eugenio 1967a. "Determinación y entorno", en Teoría del lenguaje y lingüistica general, $2^{\text {a }}$ ed., Gredos, Madrid, pp. 282-323.

Coseriu, Eugenio 1978. "El estudio funcional del vocabulario (compendio de lexemática)", en Gramática, semántica, universales, Gredos, Madrid, pp. 206-238.

Coseriu, Eugenio 1978a. "Semántica, forma interior del lenguaje y estructura profunda”, en Gramática, semántica, universales, Gredos, Madrid, pp. 112-127.

Coseriu, Eugenio 1978b. "Semántica y gramática”, en Gramática, semántica, universales, Gredos, Madrid, pp. 128-147.

Coseriu, Eugenio 1981. "Introducción al estudio estructural del léxico", en Principios de semántica estructural. Versión española de M. Martínez Hernández, $2^{a}$ ed., Gredos, Madrid, pp. 87-142.

Coseriu, Eugenio 1981a. Lecciones de lingüistica general. Versión española de J. M. Azáceta y García de Albéniz, Gredos, Madrid.

Coseriu, Eugenio 1981b. "Significado y designación a la luz de la semántica estructural”, en Principios de semántica estructural. Versión española de M. Martínez Hernández, 2ª ed., Gredos, Madrid, pp. 185-209.

Coseriu, Eugenio 1987. "Palabras, cosas y términos", en In memoriam Inmaculada Corrales. Estudios lingüisticos, Universidad de la Laguna, Santa Cruz de Tenerife, t. 1, pp. 175-185.

Cuartero Otal, Juan 2007. "Sobre estados y clases de estados", en Vernetzungen: Bedeutung in Wort, Satz und Text, Festschrift für Gerd Wotjak zum 65. Geburtstag, 2. Hrsg. Juan Cuartero Otal und Martina Emsel, Peter Lang, Frankfurt/M., pp. 111-122. 
Cuartero Otal, Juan 2011. "Pero, ¿cómo podemos reconocer los estados?”, en Aspectualidad - transitividad - referencialidad: las lenguas románicas en contraste. Eds. Valeriano Bellosta von Colbe y Marco García García, Peter Lang, Frankfurt/M., pp. 15-40.

Cuartero Otal, JuAn en preparación. La distinción entre predicados télicos y atélicos.

Cuartero Otal, Juan y M. Carmen Horno Chéliz 2011. "Estados, estatividad y perífrasis", en Estudios sobre perífrasis y aspecto. Eds. Juan Cuartero Otal et al., Peniope, München, pp. 225-248.

Cuartero Otal, Juan y M. Carmen Horno Chéliz 2012. "Estructura subeventiva y tipos de estados", en Tradición y progreso en la Lingüistica General. Coords. Emilio Ridruejo et al., Departamento de Lengua Española de la Universidad de Valladolid, Valladolid, pp. 93-111.

Cuervo, M. Cristina 2003. Datives at large, MIT, https://www.academia. edu/ 9159557/ Datives_at_Large [consultado el 12 de julio de 2018].

Cuervo, M. Cristina 2008. "La alternancia causativa y su interacción con argumentos dativos", Revista de Lingüistica Teórica y Aplicada, 46, 1, pp. 55-79, http:/ /dx.doi.org/ 10.4067/ S0718-48832008000100004.

Cuervo, M. Cristina 2014. "Alternating unaccusatives and the distribution of roots”, Lingua, 141, pp. 48-70, doi: 10.1016/j.lingua.2013.12.001.

Cuervo, M. Cristina 2015. "Causation without a CAUSE", Syntax, 18, 4, pp. 388-424, https://doi.org/10.1111/synt.12115.

Cunha, L. Filipe 2004. Semântica das predicações estativas. Para uma caracterização aspectual dos estados, Universidad de Oporto, https://repositorioaberto.up.pt/handle/10216/18379 [consultado el 12 de julio de 2018].

Delbecque, Nicole \& Béatrice Lamiroy 1996. "Towards a typology of the Spanish dative", en Casus and grammatical relations across languages. Eds. William van Belle \& Willy van Langendonck, John Benjamins, Amsterdam, t. 1, pp. 73-117.

Devís Márquez, P. Pablo 2009. "Determinación y complementación del nombre propio en español”, Nueva Revista de Filología Hispánica, 57, 2, pp. 441-488, doi: http:// dx.doi.org/ 10.24201/ nrfh.v57i2.2422.

Devís Márquez, P. Pablo 2017. "Las denominadas construcciones con sey verbos de alternancia causativa en español”, Neuphilologische Mitteilungen, 2, 118, pp. 405-445.

D’Introno, Francesco et al. 2007. "Aspectos sintácticos y semánticos del pronombre se”, Boletín de Lingüistica, 19, 28, pp. 5-25.

DowTy, DAVID R. 1979. Word meaning and Montague grammar, Kluwer, Dordrecht.

DowTy, DAVID R. 1991. “Thematic proto-roles and argument selection”, Language, 67 , pp. 547-619, doi: 10.2307/415037.

Escobar, Linda \& Vincent TorRens 2007. "On the acquisition of clitic se and aspect in Spanish", en The acquisition of Romance languages. Eds. Sergio Baauw, Jacqueline van Kampen \& Manuela Pinto, Netherlands Graduate School of Linguistics, Utrech, pp. 59-71.

Fernández Lagunilla, Marina y Elena de Miguel 1999. "Relaciones entre el léxico y la sintaxis: adverbios de foco y delimitadores aspectuales", Verba, 26, pp. 97-128. 
Fernández Leborans, M. Jesús 1999. "El nombre propio", en Gramática descriptiva de la lengua española. Dirs. Ignacio Bosque y Violeta Demonte, Espasa, Madrid, t. 1, pp. 77-128.

Fernández Ramírez, Salvador 1986. Gramática española. T. 4: El verbo y la oración, ordenado y completado por I. Bosque, $2^{\text {a }}$ ed., Arco/Libros, Madrid.

Fernández Soriano, Olga 1999. "Two types of impersonal sentences in Spanish: Locative and dative subjects", Syntax, 2, pp. 101-140, doi: https://doi.org/10.1111/1467-9612.00017.

Ferrater Mora, José 1979. Diccionario de filosofía, t. 1, Alianza Editorial, Madrid.

GARCía Fernández, Luis 2011. "Algunas observaciones sobre se aspectual”, Estudios sobre perífrasis y aspecto. Eds. Juan Cuartero Otal et al., Peniope, München, pp. 43-71.

García Fernández, Luis 2011a. "Los valores de $s e$ : ¿es un caso de $s e$ aspectual todo aquel que lo parece?", en 60 problemas de gramática dedicados a Ignacio Bosque. Coords. Escandell Vidal, M. Victoria, Manuel Leonetti Jungl y M. Cristina Sánchez López, Akal, Madrid, pp. 185-190.

García Fernández, Luis 2015. "Some reflections on verbs with clitic increase: Verbs of motion", en Verb classes and aspect. Eds. Elisa Barrajón López et al., John Benjamins, Philadelphia, pp. 264-287.

García Miguel, José M. 1985. "La voz media en español: las construcciones pronominales con verbos transitivos", Verba, 12, pp. 307-343, http:// hdl.handle.net/10347/4916.

GARRIDO, JoAQUín 1996. "Sintagmas nominales escuetos", en El sustantivo sin determinación. La ausencia del determinante en la lengua española. Ed. Ignacio Bosque, Visor, Madrid, pp. 269-338.

Gary-Prieur, Marie-N. 1994. Grammaire du nom propre, Presses Universitaires de France, Paris.

Gómez López, Paula 1993. "La expresión de la pluralidad y las clases de predicados en huichol", Función, 13/14, pp. 135-194.

González Vergara, Carlos 2012. "El clítico se en las oraciones no reflexivas en español”, en El funcionalismo en la teoría lingüistica: la Gramática del Papel y la Referencia, Akal, Madrid, pp. 127-151.

Gooch, Anthony 1982. "Valores semánticos del pronombre reflexivo en el español moderno", en Actas del cuarto Congreso Internacional de Hispanistas. Coord. Eugenio de Bustos, Universidad de Salamanca, Salamanca, t. 1, pp. 695-702.

Grice, H. Paul 1975. "Logic and conversation", en Syntax and semantics. T. 3: Speech acts. Eds. Peter Cole \& Jerry L. Morgan, Academic Press, New York, pp. 41-58.

Gutiérrez Ordóñez, Salvador 1977-1978. "Sobre los «dativos superfluos»", Archivum, 27/28, pp. 415-452.

Gutiérrez Ordóñez, Salvador 1999. "Los dativos”, en Gramática descriptiva de la lengua española. Dirs. Ignacio Bosque y Violeta Demonte, Espasa, Madrid, t. 2, pp. 1855-1930.

Hernández Alonso, César 1984. Gramática funcional del español, Gredos, Madrid. 
Hernández Alonso, César 1995. Nueva sintaxis de la lengua española, Ediciones Colegio de España, Salamanca.

Horn, Laurence R. 2007. "Toward a Fregean pragmatics: Voraussetzung, nebengedanke, andeutung”, en Explorations in pragmatics: Linguistic, cognitive, and intercultural aspects. Eds. Istvan Kecskes \& Laurence Horn, Mouton de Gruyter, Berlin, pp. 26-69.

Horno Chéliz, M. Carmen y Juan Cuartero Otal 2010. "Un modelo lexicalista de la estatividad verbal”, en La gramática del sentido: léxico y sintaxis en la encrucijada. Eds. José F. Val Álvaro y M. Carmen Horno Chéliz, Prensas Universitarias de Zaragoza, Zaragoza, pp. 77-104.

Huidobro, Susana \& Jonathan E. MacDonald 2007. "Two properties of Spanish non-argumental clitic pronouns", en XVII Colloquium on Generative Grammar (Girona 13-15 June, 2007), 32-34, https: / / www.academia. edu/ 852053/ Two_properties_of_Spanish_non-argumental_clitic_ pronouns_[consultado el 14 de julio de 2018].

JACKENDOFF, RAY S. 1972. Semantic interpretation in Generative Grammar, The MIT Press, Cambridge.

JACKENDOFF, RAY S. 1996. "The proper treatment of measuring out, telicity, and perhaps even quantification in English", Natural Language and Linguistic Theory, 14, pp. 305-354, doi: https:// doi.org/ 10.1007/ BF00133686.

Kempchinsky, Paula 2004. "Romance $s e$ as an aspectual element", en Contemporary approaches to Romance linguistics. Eds. Julie Auger et al., John Benjamins, Amsterdam-Philadelphia, pp. 239-256, doi: https:/ / doi.org/ 10.1075 / cilt.258.13kem.

Krifka, Manfred 1989. "Nominal reference, temporal constitution and quantification in event semantics", en Semantics and contextual expressions. Eds. Renate Bartsch et al., Foris, Dordrecht, pp. 75-115.

KrifKA, MANFred 1992. "Thematic relations as links between nominal reference and temporal constitution”, en Lexical matters. Eds. Ivan A. Sag \& Anna Szabolcsi, University of Chicago Press, Chicago, pp. 29-53.

KrIFKA, MANFRED et al. 1995. "Genericity: An introduction", en The generic book. Eds. Gregory N. Carlson \& Francis J. Pelletier, University of Chicago Press, Chicago, pp. 1-125.

Kupferman, Lucien 1991. "Structure événementielle de l'alternance un / $\varnothing$ devant les noms humains attributs", Langages, 25, 102, pp. 52-75, doi: 10.3406/ lgge.1991.1599.

LACA, BRenda 1996. "Acerca de la semántica de los plurales escuetos del español”, en El sustantivo sin determinación. La ausencia del determinante en la lengua española. Ed. Ignacio Bosque, Visor, Madrid, pp. 241-268.

LACA, BRENDA 1999. "Presencia y ausencia de determinante", en Gramática descriptiva de la lengua española. Dirs. Ignacio Bosque y Violeta Demonte, Espasa, Madrid, t. 1, pp. 891-928.

Lázaro Carreter, Fernando 1964. "Problemas de terminología lingüística”, en Presente y futuro de la lengua española, Cultura Hispánica, Madrid, t. 2, pp. 383-392.

LeOnetti, Manuel 1999. "El artículo", en Gramática descriptiva de la lengua española. Dirs. Ignacio Bosque y Violeta Demonte, Espasa, Madrid, t. 1, pp. 787-890. 
Longobardi, Giuseppe 1994. "Reference and proper names: A theory of $\mathrm{N}$-movement in syntax and logical form", Linguistic Inquiry, 25, 4, pp. 609-665.

MacDonald, Jonathan E. 2017. "Spanish aspectual se as an indirect object reflexive: The import of atelicity, bare nouns, and leista PCC repairs", Probus, 29, 1, pp. 73-118 (publicado en línea en 2016), doi: https:/ / doi. org/10.1515/probus-2015-0009.

Maldonado, Ricardo 1997. "Dos trayectos, un sentido. Rutas conceptuales de la accidentalidad", en Varia lingüistica y literaria. 50 años del Centro de Estudios Lingüisticos y Literarios. Eds. Rebeca Barriga Villanueva y Pedro Martín Butragueño, El Colegio de México, México, t. 1, pp. 165-189.

Maldonado, Ricardo 2006. A media voz. Problemas conceptuales con el clítico "se", Universidad Nacional Autónoma de México, México.

Martín ZorraQuino, M. ANTONia 1979. Las construcciones pronominales en español. Paradigma y desviaciones, Gredos, Madrid.

Masullo, Pascual J. 1996. "Los sintagmas nominales sin determinante: una propuesta incorporacionista”, en El sustantivo sin determinación. La ausencia del determinante en la lengua española. Ed. Ignacio Bosque, Visor, Madrid, pp. 169-200.

Miguel, Elena de 1999. "El aspecto léxico", en Gramática descriptiva de la lengua española. Dirs. Ignacio Bosque y Violeta Demonte, Espasa Calpe, Madrid, t. 2, pp. 2977-3060.

Miguel, Elena de y Marina Fernández Lagunilla 2000. "El operador aspectual se", Revista Española de Lingüistica, 30, 1, pp. 13-43.

Minguell, A. Esther 2012. "Acerca de las funciones semánticas y sintácticas del clítico se y su estatus en la gramática del español”, Recial, 3, 3, https://revistas.unc.edu.ar/ index.php/ recial/ issue/ view/688 [consultado el 12 de julio de 2018].

Molina Redondo, José A. De 1974. Usos del "se". Cuestiones sintácticas y léxicas, $2^{a}$ ed., SGEL, Madrid.

Montes Giraldo, J. JoAQuín 2003. "El se del español y sus problemas", Estudios Filológicos, 38, pp. 121-137, doi: http:// dx.doi.org/ 10.4067/ S007117132003003800008.

Morimoto, Yuko 2008. "Me estuve quieto: el concepto de estado y el llamado se aspectual”, en Actas del XXXVII Simposio Internacional de la Sociedad Española de Lingüistica (SEL). Eds. Inés Olza Moreno et al., Servicio de Publicaciones de la Universidad de Navarra, Pamplona, pp. 591-599.

Narbona, Antonio 1984. "Construcciones pronominales transitivas no reflexivas en español”, Alfinge. Revista de Filología, 2, pp. 163-190, http:/ / hdl.handle.net/10396/16618.

Nishida, Chiyo 1994. "The Spanish reflexive clitic se as an aspectual class marker", Linguistics, 32, pp. 425-458, doi: 10.1515/ ling.1994.32.3.425.

Otero, Carlos P. 1968. "El otro se", en Actas del XI Congreso de Lingüistica y Filología Románicas. Coords. Antonio Quilis, Ramón B. Carril y Margarita Cantarero, CSIC, Madrid, t. 4, pp. 1841-1852.

Otero, Carlos P. 1999. "Pronombres reflexivos y recíprocos", en Gramática descriptiva de la lengua española. Dirs. Ignacio Bosque y Violeta Demonte, Espasa Calpe, Madrid, t. 1, pp. 1427-1517. 
Otero, Carlos P. 2002. "Facetas de se", en Las construcciones con "se". Ed. Cristina Sánchez López, Visor, Madrid, pp. 165-205.

Paz Lourençoni, Débora C. y Adriana Leitão Martins 2017. “O operador aspectual se no espanhol do Chile: contextos semánticos e morfossintáticos de uso”, Fórum Linguístico, 14, 2, pp. 2076-2095, doi: https:// doi.org/ 10.5007/ 1984-8412.2017v14n2p2076.

Pena, Jesús 1982 "La voz en español. Intento de caracterización”, Verba, 9, pp. 215-252, http://hdl.handle.net/ 10347/ 4967.

PÉrEz VÁzQUEZ, M. ENRIQUETA 2002. "El pronombre aspectual con verbos de movimiento y cambio de estado en español. (Posibilidad de una explicación pragmática)", Quaderni del Laboratorio di Linguistica della Scuola Normale Superiore di Pisa, 3, pp. 189-213.

Pérez VÁzquez, M. EnRiQueta 2007. "Pronombres superfluos. Dativos benefactivos en español e italiano", en Partículas/Particelle. Estudios de lingüistica contrastiva español e italiano. Ed. Félix San Vicente, Clueb, Bologna, pp. 11-34.

Pustejovsky, James 1991. "The syntax of event structure”, Cognition, 41, pp. 47-81, doi: https://doi.org/10.1016/0010-0277(91)90032-Y.

PylkkÄNen, LiIna 2002. Introducing arguments, MIT, http:/ /www.ai.mit.edu/ projects/ dm/ theses/ pylkkanen02.pdf [consultado el 12 de julio de 2018].

Pylkkänen, Liına 2008. Introducing arguments, The MIT Press, Cambridge. Quine, Willard V.O. 1960. Word and object, The MIT Press, Cambridge.

RAE y ASALE 2009. Nueva gramática de la lengua española, Espasa Libros, Madrid, 2 ts.

Rigau, GEMma 1994. "Les propietats dels verbs pronominals", Els Marges, 50, pp. 29-39.

Rigau, GEMma 1999. "La estructura del sintagma nominal: los modificadores del nombre", en Gramática descriptiva de la lengua española. Dirs. Ignacio Bosque y Violeta Demonte, Espasa Calpe, Madrid, t.1, pp. 311-362.

Romero Pascual, Cristina e Ismael Teomiro García 2012. "La relación entre estructura eventiva y papeles temáticos: el se aspectual del español", Revista de Filología Románica, 29, 2, pp. 233-243, doi: 10.5209/ rev_ RFRM.2012.v29.n2.40156.

SÁnchez López, Cristina 2002. "Las construcciones con se. Estado de la cuestión", en Las construcciones con "se”. Ed. Cristina Sánchez López, Visor, Madrid, pp. 13-163.

Sanz, Montserrat 2000. Events and predication, John Benjamins, Amsterdam, doi: 10.1017/S0272263104281050.

Sanz, Monteserrat e Itziar Laka 2002. "Oraciones transitivas con se. El modo de acción en la sintaxis", en Las construcciones con "se". Ed. Cristina Sánchez López, Visor, Madrid, pp. 311-337.

Schroten, Jan 1972. Concerning the deep structures of Spanish reflexive "sentences", Mouton, The Hague.

Selkirk, Elisabeth O. 1984. Phonology and syntax: The relation between sound and structure, The MIT Press, Cambridge.

Silvagni, Federico 2017. Entre estados y eventos. Un estudio del aspecto interno del español, tesis, Universitat Autònoma de Barcelona, https://ddd.uab. 
cat/ pub/ tesis/2017/ hdl_10803_405516/ fesi1de1.pdf [consultado el 12 de diciembre de 2018].

Silvagni, Federico 2018. "Sobre la distinción entre Individuo/ Estadio y su relación con ser y estar", Revista Española de Lingüistica, 48, pp. 15-56.

STrozer, Judith R. 1976. Clitics in Spanish, UCLA, https:/ / search-proquestcom.bibezproxy.uca.es / docview/302819850?accountid=14495 [consultado el 12 de julio de 2018].

Suñer, Margarita 1973. Non-paradigmatic se's in Spanish, Indiana University, https://search-proquest-com.bibezproxy.uca.es/docview/30264940 2? accountid=14495, [consultado el 12 de julio de 2018].

Suñer, MARGARITA 1982. The syntax and semantics of presentational sentence-types in Spanish, Georgetown University Press, Washington, DC.

Tenny, CARol 1992. "The aspectual interface hypothesis", en Lexical matters. Eds. Ivan A. Sag \& Anna Szabolcsi, University of Chicago Press, Chicago, pp. 1-27.

Tenny, Carol 1994. Aspectual roles and the syntax-semantic interface, Kluwer, Dordrecht.

Teomiro García, Ismael 2010. Anaphors at the interfaces. A comparative study of the variation of the anaphoric systems of English, Dutch and Spanish, Universidad Autónoma de Madrid, https://repositorio.uam.es/ handle/ 10486/10311 [consultado el 12 de julio de 2018].

Teomiro García, Ismael \& Cristina Romero Pascual 2012. "Theta meets aspect: The Spanish aspectual «se» with consumption verbs", Topics in Linguistics, 10, pp. 20-27.

Torrego, Esther 1989. "Unergative-unaccusative alternations in Spanish", en Functional heads and clause structure. Eds. Itziar Laka \& Anoop Mahajan, The MIT Press, Cambridge, pp. 253-272. (MIT Working Papers in Linguistics, 10).

Trebisacce, Romina 2014. "Delimitación eventiva en español: un estudio sobre el se aspectual”, Exlibris, 3, pp. 198-206.

Vendler, Zeno 1957. "Verbs and times", The Philosophical Review, 66, 2, pp. 143-160. [También en Linguistics in philosophy, Cornell University Press, Ithaca, 1967, pp. 97-121].

Verkuyl, Henk 1993. A theory of aspectuality. The interaction between temporal and atemporal structure, Cambridge University Press, Cambridge.

ZaGona, KAREN 1996. "Compositionality of aspect: Evidence from Spanish aspectual se", en Aspects of Romance linguistics: Selected papers from the XXIV linguistic symposium on Romance languages. Eds. Claudia Parodi et al., Georgetown University Press, Washington, DC, pp. 475-529.

Zubizarreta, M. Luisa 1998. Prosody, focus, and word order, The MIT Press, Cambridge.

Zubizarreta, M. Luisa 1999. "Las funciones informativas: tema y foco", en Gramática descriptiva de la lengua española. Dirs. Ignacio Bosque y Violeta Demonte, Espasa, Madrid, t. 3, pp. 4215-4244. 